\title{
Un bicentenario del café en Colombia: estrategia competitiva y cambio estructural
}

\section{A bicentenary of coffee in Colombia: competitive strategy and structural change ${ }^{\star}$}

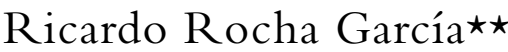

Resumen: Un análisis empírico de la estrategia exportadora de Colombia frente a Brasil en el mercado cafetero durante 1826-2018, considerando una competencia oligopolista por productos diferenciados. La relación de cointegración bilateral de las exportaciones según precios, costos, demanda y cambios en la política comercial fue estimada mediante un modelo de mínimos cuadrados ordinarios dinámico.Los resultados sugieren que Colombia transitó desde ser un incipiente exportador y tomador de precios, hasta convertirse en oligopolista del café suave ante la política de valorización del Brasil. Luego de la ruptura del Acuerdo Internacional del Café, ambos países protagonizaron un intercambio de roles, cuyos efectos se simulan según un escenario contrafactual.

Palabras clave: Café. Exportaciones. Colombia. MCOD. Política comercial estratégica.

Abstract: An empirical analysis of the export strategy of Colombia against Brazil in the coffee market during 1826-2018, considering an oligopolistic competition for differentiated products. The relationship of bilateral cointegration of exports according to prices, costs, demand, and changes in trade policy was estimated using a dynamic ordinary least squares model. The results suggest that Colombia went from being an incipient exporter and price taker, until becoming an oligopolist of soft coffee before Brazil's valorization policy.After the breakdown of the International

\footnotetext{
* Submissão: 25/09/2019 | Aprovação: 05/12/2020 | DOI: 10.29182/hehe.v24i2.696

Investigación independiente realizada durante el primer semestre de 2019. Una versión corregida de la publicada en el $\mathrm{N}^{\circ} 30$ de la serie Investigaciones y Productos del FCE - CID de la Universidad Nacional. Se agradecen los valiosos comentarios recibidos de dos evaluadores anónimos, también de Fernando Mesa, Alexánder Rocha, Mario Samper, Charles Bergquist, Donald MacLaren y Lewis Jarvis, así como de los asistentes a los seminarios del CID y del DNP realizados el 3 de julio y el 26 de septiembre de 2019, respectivamente. Los errores, opiniones, limitaciones y omisiones son responsabilidad exclusiva del autor y no comprometen a las personas e instituciones aquí mencionadas.

$\star \star$ Investigador Asociado, Centro de Investigaciones para el Desarrollo de la Facultad de Ciencias Económicas de la Universidad Nacional de Colombia | E-mail: ricardorochagarcia@yahoo.es | ORCID 00000002-6558-759X
} 
Coffee Agreement, starring in an exchange of roles, whose effects are simulated according to a counterfactual scenario.

Keywords: Coffee. Exports. Colombia. DOLS. Strategic Trade Policy.

JEL: F14; L13; N76 


\section{Introducción}

La inserción de Colombia en el mercado mundial cafetero ha experimentado significativas transformaciones durante su primer bicentenario. Durante la primera mitad del siglo XIX el café del departamento de Santander se exportaba porVenezuela, quien era el principal productor de café suave y fue superado por Colombia tras la Primera Guerra Mundial. Posteriormente, las exportaciones colombianas crecieron hasta la ruptura del Acuerdo Internacional del Café (AIC) en 1989, cuando alcanzaron las de Brasil. Desde entonces, Colombia ha perdido mercado y finalmente ha enfrentado una postración del precio internacional.

Un tema que aquí se revisita desde la perspectiva de la imperfección de los mercados, la teoría del comercio internacional y el análisis empírico de las series de tiempo, la cual tiene la finalidad de contribuir al entendimiento de la historia de la estrategia competitiva del café en el mercado internacional, utilizando técnicas econométricas en presencia de cointegración y cambios estructurales, con la finalidad de caracterizar la política comercial sobre sus resultados.

Se trata de una aproximación de largo plazo a la competencia oligopolística en torno a la inserción de Colombia al mercado cafetero y su pugna competitiva con Brasil. El análisis cuantitativo comprendió dos siglos de transformaciones en el mercado de uno de los commodities emblemáticos de la agricultura tropical. Un siglo XIX enmarcado en la expansión del mercado y la liberación del comercio colonial, donde Colombia era un incipiente tomador de precios y Brasil culmina como monopolista. A partir del siglo pasado la política de valorización limitó la producción brasileña, permitiéndole a Colombia tornarse en oligopolista protagonizando ambos países una pugna competitiva, a pesar de los acuerdos propiciados por la Gran Depresión, la Segunda Guerra Mundial y la Guerra Fría. Un oligopolio que trascendió la ruptura del Pacto Internacional del Café, con intercambio de roles y un reacomodamiento del mercado con evidentes resultados de la política comercial.

Para lo anterior, se estructuró un texto según las siguientes secciones. En la primera, se presenta una breve reseña de los antecedentes históricos de la inserción de Colombia al mercado cafetero y su rivalidad con Brasil. Luego se hace referencia a la estrategia competitiva en un mercado oligopólico y con productos diferenciados, ajustando precios y cantidades, desde la óptica de la política comercial estratégica. 
En la tercera sección se describe la información de ambos países para 1826-2018, donde fue necesario interpolar y empalmar diferentes series de la inflación, tasa de cambio, así como de precios y cantidades exportadas. En la cuarta sección, mediante pruebas estadísticas se identificó cambios estructurales y se analizó su correspondencia con la política comercial y su estacionariedad. Una quinta sección que muestra la estimación de la relación de cointegración usando un modelo dinámico de mínimos cuadrados ordinarios, con resultados para el período completo, contrastando subperíodos y simulando un escenario contrafactual para 1988-2018. Finalmente, una sección de conclusiones.

\section{Antecedentes}

A finales del siglo XVIII la exportación de café ya se reportaba en el comercio colonial (Duran, 1794). Desde entonces la historia de la inserción de Colombia al mercado internacional podría caracterizarse en tres grandes etapas, comenzando como un productor tomador de precios ante el monopolio de Brasil, para luego convertirse en competidor oligopolista y recientemente adoptando la política de valorización (Tabla 1).

La primera etapa se remonta a la incursión de Colombia al mercado como tomador de precios (Gráfica 1). Entonces la variedad arábiga había experimentado múltiples mutaciones en América y el Caribe, con la diferenciación del cultivo entre los bosques de montaña y la producción a plena exposición solar (Topik, 2003).

Tabla 1 - Inserción en el mercado cafetero

\begin{tabular}{|c|c|c|c|c|}
\hline Etapa & Inicio & $\begin{array}{c}\text { Principales } \\
\text { competidores }\end{array}$ & $\begin{array}{l}\text { Diferenciación } \\
\text { del mercado }\end{array}$ & $\begin{array}{l}\text { Respuesta } \\
\text { competitiva }\end{array}$ \\
\hline $\begin{array}{l}\text { Tomador de } \\
\text { precios }\end{array}$ & $\begin{array}{l}\text { Independencia } \\
1821\end{array}$ & $\begin{array}{l}\text { Brasil, el Caribe } \\
\text { y Venezuela }\end{array}$ & $\begin{array}{l}\text { Variedades } \\
\text { americanas y el } \\
\text { café suave }\end{array}$ & $\begin{array}{l}\text { Cultivo en } \\
\text { Santander y } \\
\text { expansión hacia el } \\
\text { interior y occidente. } \\
\text { Mejoramiento de la } \\
\text { infraestructura de } \\
\text { comunicaciones y } \\
\text { transporte. }\end{array}$ \\
\hline
\end{tabular}


Tabla 1 - Inserción en el mercado cafetero

\begin{tabular}{l|l|l|l|l}
\hline \multicolumn{1}{c|}{ Etapa } & \multicolumn{1}{|c|}{ Inicio } & $\begin{array}{c}\text { Principales } \\
\text { competidores }\end{array}$ & $\begin{array}{l}\text { Diferenciación } \\
\text { del mercado }\end{array}$ & \multicolumn{1}{c}{$\begin{array}{c}\text { Respuesta } \\
\text { competitiva }\end{array}$} \\
\hline $\begin{array}{l}\text { Competencia } \\
\text { oligopolista }\end{array}$ & $\begin{array}{l}\text { Valorización } \\
\text { del café del } \\
\text { Brasil a partir } \\
\text { de } 1903\end{array}$ & Brasil & $\begin{array}{l}\text { Preferencia por } \\
\text { mezclas y marcas. } \\
\text { Concentración de } \\
\text { la manufactura y la } \\
\text { comercialización. }\end{array}$ & $\begin{array}{l}\text { Expansión de áreas y } \\
\text { exportaciones, } \\
\text { comercialización y } \\
\text { diferenciación. } \\
\text { Diversificación } \\
\text { productiva }\end{array}$ \\
\hline $\begin{array}{l}\text { Valorización } \\
\text { del café suave }\end{array}$ & $\begin{array}{l}\text { Ruptura del } \\
\text { AIC en } 1989\end{array}$ & $\begin{array}{l}\text { Etiopía, Uganda, } \\
\text { Honduras y } \\
\text { Perú }\end{array}$ & $\begin{array}{l}\text { Demanda por café } \\
\text { instantáneo. }\end{array}$ & $\begin{array}{l}\text { Estabilización y } \\
\text { valorización de la } \\
\text { oferta. Migración } \\
\text { hacia el } \\
\text { suroccidente. }\end{array}$ \\
\hline
\end{tabular}

Fuente: elaboración del autor.

\section{Gráfica 1 - Exportaciones de Colombia y Brasil, precios $y$ cantidades en 1826-2018}

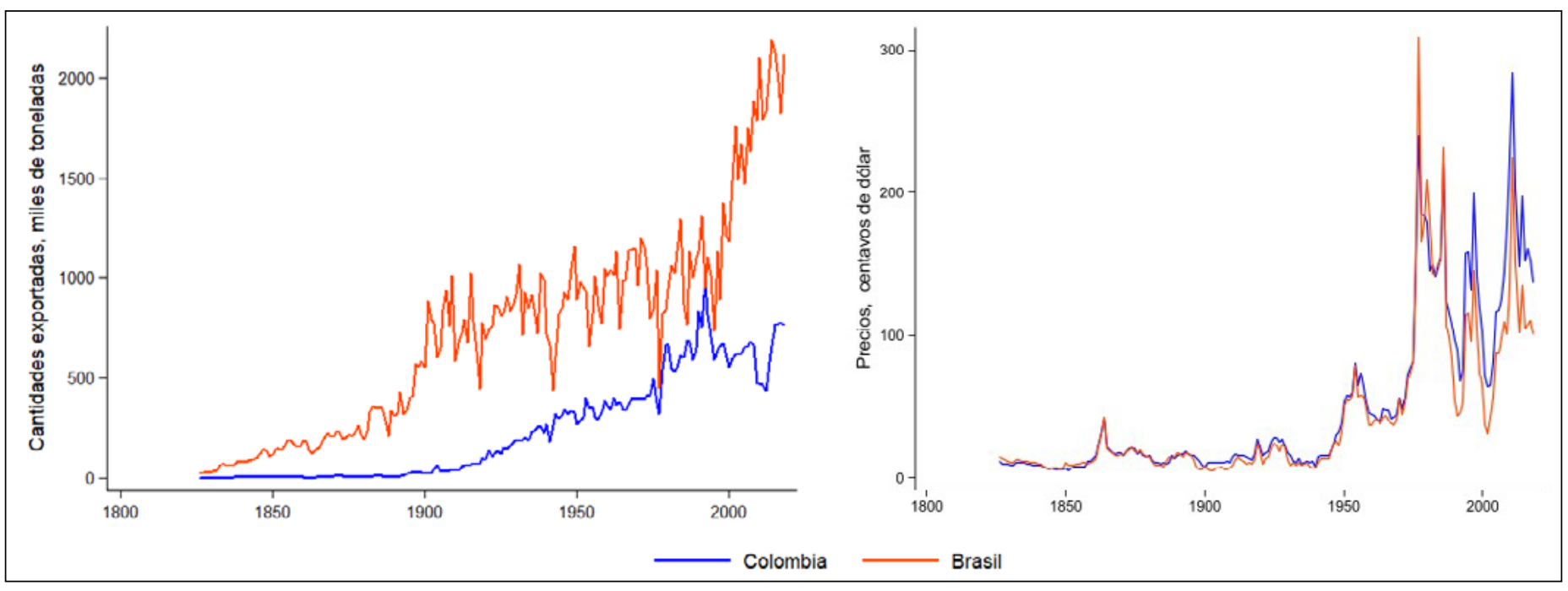

Fuente: sección 3. Elaboración del autor.

A comienzos del siglo XIX se reportaban cultivos comerciales en Santander (Federecafé, 1958). En 1821 el gobierno de Colombia estableció exenciones arancelarias a las exportaciones de café (Palacios; Safford, 2002) y para 1826 reportó ventas a los Estados Unidos (Secretary of Treasury, 1827). En la década siguiente, la oferta mundial recién establecida en el Caribe iniciaría su migración hacia el Brasil,Venezuela, Colombia y Costa Rica (Samper, 2003). 
En este período emerge Brasil como líder de la oferta mundial y los Estados Unidos como país consumidor. El pánico de la Bolsa de Londres de 1825 desencadenó una depresión en los precios del café (Silberling, 1919) la cual se prolongó hasta 1851. Entonces la comercialización internacional del café en grano, se realizaba entre una vasta y heterogénea red de productores y acopiadores locales y los mercados de Ámsterdam y Nueva York (Topik; Gervase, 2003). Entre 1834 y 1858 la mayor parte de las incipientes exportaciones se realizaron por Cúcuta y correspondían al cultivo en Santander (Ocampo, 1981).

En esta etapa exportadora Colombia habría sido seguidor de su vecino Venezuela, entonces el principal exportador de café suave (Samper, 2003). La segunda mitad del siglo XIX inició con la disminución de importaciones de los Estados Unidos durante la Guerra de Secesión y la consecuente expansión de su mercado (Mason, 2004). Luego, Colombia aumentó su exportación con la expansión del cultivo hacia Antioquia, Cundinamarca, Tolima, Caldas y el Valle.

Una dinámica favorecida por los mercados de Hamburgo, Le Havre y Londres, así como por la creación de la bolsa de futuros de Nueva York en 1882, la introducción del telégrafo y el cable submarino por Panamá, la navegación a vapor por el Río Magdalena y la construcción de ferrocarriles. Los vínculos comerciales se estrecharon entre importadores y productores, estableciendo sedes en la contraparte (Mason, 2004), con la subsecuente diversificación del comercio y el acceso al crédito (Beyer, 1948). Ambos países se insertaron al comercio internacional del café a través del legado colonial de la hacienda y sus redes sociales en medio de las diferencias que representaba cultivar en el departamento colombiano de Santander o en el estado brasileño de São Paulo (Carreño, 2015).

El precio del café se desplomó entre las crisis financieras de 1873-1879 y de 1884 (Bergquist, 1999), luego repuntó a partir de 1887 por una helada en el Brasil y la plaga de la Roya en Java y Ceilán (Topik, 2003) hasta la crisis de sobreproducción de 1896 y la subsecuente postración del precio hasta el desplome de la bolsa de Nueva York en 1901.

Una segunda etapa comienza cuando se alcanzan las exportaciones de Venezuela por la Primera Guerra Mundial y la producción petrolera, y Colombia le comienza a ganar mercado a Brasil, aprovechando su política de valorización y retención de las exportaciones, sumándosele como segundo productor mundial. Entonces habría predominado una competencia oligo- 
polística por productos diferenciados ajustando cantidades, donde la estrategia de reducir la oferta brasileña sustentaba la estrategia de ampliar la producción de café colombiano.

Desde entonces y hasta finales de siglo, la competencia se ajustó en las cantidades, Brasil duplicó sus ventas externas y las exportaciones de café suave Colombia se multiplicaron por veinte. Durante esa etapa el mercado experimentó numerosas perturbaciones exógenas derivadas del clima, las guerras mundiales y las crisis financieras. De hecho, las heladas del Brasil asociadas al ciclo solar afectaron adversamente la producción en 18 ocasiones. Otro tanto ocurrió con los precios del café ante las crisis financieras de 1901, 1907, 1920, 1929, 1936, 1974 у 1987.

En 1903 ante el exceso de oferta, el Brasil quien representaba el 80\% de la oferta mundial, intervino por primera vez el mercado estableciendo impuestos tendientes a reducir las exportaciones e inducir mayores precios dada la inelasticidad de la demanda (Topik, 2003,). Su posterior implementación a través de la retención y destrucción de excedentes en 1907-1913 y 1923-1930, conocida como la política de valorización implicó perder participación en el mercado a manos del café suave (Abreu; Bevilaqua, 1996).

La diferenciación de la calidad del café de Colombia ya se reflejaba en la cotización desde el final del siglo XIX y se favoreció desde 1907 con la exigencia de reportar el puerto de origen de las importaciones en los Estados Unidos (Topik, 2003).

La pugna competitiva entre Brasil y Colombia también desplegó instituciones y políticas para promover la actividad cafetera. En Brasil primero desde los gobiernos estatales, luego a nivel federal creó el Departamento Nacional del Café en 1933 y posteriormente el Instituto Brasileño del Café en 1952. Mientras que en Colombia se creó la Federación Nacional de Cafeteros (Federecafé) en 1927 una agremiación de productores dotada de parafiscalidad y cuyos intereses ya se promovían desde la Sociedad de Agricultores de Colombia.

Luego de la Primera Guerra Mundial se hizo evidente la rivalidad comercial entre ambos países, principalmente por el mercado de los Estados Unidos (Ocampo, 1989). En Colombia la comercialización abandonó el tradicional sistema consignatario, arribaron nuevas firmas extranjeras y la Federación Nacional de Cafeteros interviene como gran acopiador y exportador a partir de los años 30 .

En Brasil las políticas de valorización basadas en la acumulación y des- 
trucción de inventarios fueron financiadas con impuestos y deuda externa, junto con el control de la tasa de cambio (Abreu; Bevilaqua, 1996; Stuhlberger, 2015). En Colombia también se establecieron políticas cambiarias que ajustaban parcialmente al precio internacional del café (Edwards, 1985).

En 1937 hubo un primer acuerdo de retención de exportaciones entre Colombia y Brasil, seguido de una guerra comercial con disminución de inventarios y caída del precio. Un pacto efímero ante la ambigüedad de sus condiciones, su costoso financiamiento y la especulación suscitada, prevaleciendo la estrategia de Federecafé de no cooperar con Brasil para reducir la oferta mundial y compartir el costo de la valorización (Bates, 1994; Robles, 2018).

Ante la Segunda Guerra Mundial, ambos países, junto con los Estados Unidos y la producción hemisférica, suscribieron el Acuerdo Interamericano del Café, utilizando cuotas hasta 1948 para estabilizar el precio. Posteriormente entre 1957 y 1958 Colombia y otros productores de suaves firmaron el Acuerdo de México y el Acuerdo Latinoamericano con Brasil, como preámbulo del Acuerdo Internacional de Café, AIC, el cual estuvo vigente entre 1962 y 1989, enmarcado dentro de la geopolítica de la Guerra Fría (Santos, 2004).

El AIC buscaba estabilizar los precios y mejorar el ingreso de la oferta, siendo suscrito entre los principales países productores y consumidores. Operaba sobre cuotas de exportaciones establecidas según la oferta histórica, certificaciones de origen, deducciones sobre cuotas futuras por excesos y un fondo para promover la diversificación productiva. Sin embargo, las cuotas vigentes durante 1961-1973 y 1979-1989 (Santos, 2004) se eludían mediante la triangulación de exportaciones, la reexportación desde países importadores y las exportaciones con descuentos a no miembros (Bohman; Jarvis, 1990). Una prácticas sistemáticas sobre las cuales el AIC tuvo un débil control y credibilidad pues carecía de sanciones efectivas por incumplimientos (Junguito, 1979).

La última etapa de la pugna competitiva es posterior a la ruptura del AIC, cuando Colombia luego de alcanzar las exportaciones de Brasil, decide estabilizar su producción, mientras Brasil y un puñado de competidores procedieron a aumentarla. Al mismo tiempo la cadena de valor se tornaba aguas abajo más concentrada y globalizada, y cambiando la diferenciación del producto.

El Acuerdo Internacional del Café finalmente colapsó por su difícil 
implementación, el fin de la Guerra Fría y la ola reformista promercado. En 1986 Brasil inició la privatización de su cadena de valor, el cooperativismo y la promoción de la expansión del cultivo en la región de El Cerrado, menos vulnerable a las heladas (De Lima, 2014), en 1990 se liquidó el Instituto Brasileño del Café y desde 1992 sus exportaciones han aumentado la participación en el mercado internacional del 27\% al 32\% en 2018.

Mientras que la respuesta estratégica de Colombia fue estabilizar su oferta, proponiéndose para 1997-2005 aumentar la productividad, mejorar la calidad del café suave, minimizar costos e inventarios, estabilizando la oferta en torno a los 13 millones de sacos de 60 kilos (Federecafé, 1997). Entre 2001 y 2008 se eliminó la sustentación del precio interno y se requirió de subsidios (Steiner; Salazar; Becerra, 2015). El cultivo migró hacia el suroccidente y disminuyó la producción a 8 millones de sacos y la participación en el mercado internacional al 6\% en 2011 (Cano et al., 2012). Entre 1992 y 2018, la cosecha colombiana pasó de 16 millones de sacos a 13.5 millones, mientras que su contribución a las exportaciones mundiales cayó del 16\% al 9\%, en medio de una postración en los estándares de vida y laborales de las regiones cafeteras (Rocha, 2014).

Desde entonces, en el mercado cafetero han cambiado la estructura y la diferenciación del producto. Apreciándose inelasticidad al precio debido a su saturación, la competencia de otras bebidas, la creciente desigualdad del ingreso y nuevos hábitos. En las mezclas se ha incrementado la participación de otros cafés suaves con menor precio, la incorporación de tecnologías para suavizar el sabor de las variedades robustas, así como la concentración de la industria y la comercialización, con una competencia vía participaciones de mercado. Además, de manera incipiente, se ha expandido el mercado de los cafés especiales por consideraciones ambientales, origen y de calidad gourmet, así como un repunte del consumo de café instantáneo. Mientras que se ha duplicado el mercado de futuros (Pelupessy, 2007).

Para esta última etapa, existe evidencia de la interacción de Colombia y Brasil en un mercado oligopólico. Para 1990-2005 se dispone de evidencia a favor de una competencia vía cantidades con información trimestral de las importaciones de café en los Estados Unidos, originarias de Colombia y Brasil, de acuerdo con un modelo de duopolio para las funciones de demanda de cada país y la maximización de beneficios, el cual fue estimado mediante un modelo econométrico estructural (Rendón, 2013), siguiendo un estudio sobre las importaciones de carne en Japón y sus interacciones con exportadores 
de Australia y los Estados Unidos (Carter; MacLaren, 1997). Siendo la competencia en mercados oligopólicos un rasgo característico de las exportaciones de Colombia (Rocha; Perilla; López, 2004).

\section{Un mercado oligopólico con productos diferenciados}

De acuerdo a lo anterior, desde el siglo pasado habrían predominado las estrategias competitivas de Colombia y Brasil propias de un mercado internacional oligopólico y en concurrencia con otros países productores; con productos diferenciados, el primero ofreciendo café suave y el segundo variedades arábigas y robustas; con costos asimétricos, el café suave es intensivo en trabajo y en la pequeña escala al interior del bosque Andino, mientras que el segundo es mecanizado y de grandes extensiones a exposición solar; el café suave se le atribuye una mejor calidad y ello se refleja en un mayor precio; siendo ambos líderes en el mercado, cada uno ajusta su oferta para maximizar sus ingresos, de acuerdo a su función productiva, el conocimiento de su rival y de la demanda mundial; además que los productores y comercializadores han agenciado su acción colectiva de manera compleja y cambiante a través de instituciones políticas, gremiales, públicas e internacionales.

Asumiendo de que ambos países habrían jugado prevalentemente según un modelo de duopolio de Cournot, donde la variable estratégica es la cantidad exportada, cada país la escoge maximizando su beneficio y da por sentado que su rival hace lo mismo, en el sentido del equilibrio de Nash.Tal como suele ocurrir con los commodities de tardío rendimiento, perecederos y con inflexibilidades en la función de producción (Carter; MacLaren, 1997).

Lo anterior, una vertiente de la teoría del comercio internacional conocida como la Política Comercial Estratégica, donde las estrategias competitivas pueden ser influenciadas por políticas comerciales a través de la acción colectiva de los productores sobre los gobiernos y de esta manera promover la competitividad en el mercado internacional (Brander, 1995).

Siguiendo a Tremblay y Horton (2012) la demanda mundial es $Q=q$ $+q^{\star}$, donde la respuesta optima de la producción de Colombia, $q$, se da en función de la de Brasil, $q^{\star}$, asumiendo que cada país se comporta como una firma representativa, la cual produce y comercializa.

Para el caso de Colombia (Brasil con asterisco) la función inversa de la demanda [1] explica el precio de las exportaciones, $p,\left(p^{\star}\right)$ según cuatro componentes: un valor mínimo, $a$; menos un parámetro $b$, multiplicado por la 
producción propia; menos la producción de Brasil, $q^{\star}$, (Colombia, $\left.q\right)$ multiplicada por un coeficiente de diferenciación del producto, $d$, cuyo valor se moverá desde cero con total diferenciación, hasta la unidad con plena homogeneidad de productos; más un parámetro $g$ asociado a la demanda $Y$ del mercado mundial.

$$
\begin{aligned}
& p=a-b q-d q^{\star}+g Y \\
& p^{\star}=a-b p^{\star}-d q+g Y
\end{aligned}
$$

Las funciones de maximización de beneficios para Colombia y Brasil [2], contemplan la diferencia entre ingresos y costos. Los primeros corresponden a las funciones inversas de la demanda [1] multiplicadas por las cantidades, $\mathrm{q},\left(\mathrm{q}^{\star}\right)$ y la tasa de cambio $e,\left(e^{\star}\right)$ con respecto al mercado exportador. Mientras que los costos en moneda local corresponden a los requerimientos de insumo, $c,\left(c^{\star}\right)$ multiplicados por los precios de los insumos, w, $\left(\mathrm{w}^{\star}\right)$ y las cantidades $\mathrm{q},\left(\mathrm{q}^{\star}\right)$.

$$
\begin{aligned}
& \pi\left(q, q^{\star}\right)=\left(a-b q-d q^{\star}+g Y\right) q e-c q w \\
& \pi^{\star}\left(q, q^{\star}\right)=\left(a-b q^{\star}-d q+g Y\right) q^{\star} e^{\star}-c^{\star} q^{\star} w^{\star}
\end{aligned}
$$

El ajuste en cantidades tipo Cournot supone que la oferta mundial cambia con el respectivo ajuste en Colombia (Brasil), asumiendo el de Brasil (Colombia) constante (Baldwin, 1997), es decir: $d Q / d x=1, d Q /\left(d x^{\star}=1\right.$, es decir, la condición de intercambiabilidad del equilibrio de Cournot-Nash que formalmente se resuelve cuando las funciones de beneficios [2] de cada país se derivan con respecto a su respectiva producción [3]:

$$
\begin{aligned}
& \frac{\partial \pi}{\partial q}=\left(a-2 b q-d q^{\star}+g Y\right) e-c w=0 \\
& \frac{\partial \pi^{\star}}{\partial q^{\star}}=\left(a-2 b q^{\star}-d q+g Y\right) e^{\star}-c^{\star} w^{\star}=0
\end{aligned}
$$

A partir de la anterior se obtiene FR (FR*) la función de reacción [4] de los aumentos (disminuciones) en la oferta de Colombia (Brasil) frente a las disminuciones (aumentos) en la producción de Brasil (Colombia).Además, 
ambas muestran para cada país la transmisión de los menores costos unitarios de los insumos expresado en divisas, $\mathrm{z} \equiv \mathrm{cw} / \mathrm{e},\left(\mathrm{z}^{\star} \equiv \mathrm{c}^{\star} \mathrm{W}^{\star} / \mathrm{e}^{\star}\right)$ y de los mayores precios hacia su aumentos en su respectiva producción. Mientras que la mayor demanda mundial y la menor diferenciación entre los dos tipos de café determinarán una mayor producción para ambos países.

$$
\begin{aligned}
& F R: q^{\star}=(a-2 b q+g Y-z) / d, \operatorname{con} z=c w / e \\
& F R^{\star}: q^{\star}=\left(a-2 d q+g Y-z^{\star}\right) / 2 b, \text { con } z^{\star}=c^{\star} w^{\star} / e^{\star}
\end{aligned}
$$

Simplificando lo anterior en las siguientes funciones lineales homogéneas [5], se asume que la distribución de la demanda entre $q$ y $q^{\star}$ es homotética, depende de $z$ y $z^{\star}$, junto con los precios $p$ y $p^{\star}$, así como de la demanda internacional, $Y$.

$$
\begin{aligned}
& q=\theta\left(p, z, q^{\star}, Y\right) \\
& q^{\star}=\theta \star\left(p^{\star}, z^{\star}, q, Y\right)
\end{aligned}
$$

Aplicando logaritmos y restando ambas expresiones, la función a estimar se reduce a [6]:

$$
\ln \frac{q=}{q^{\star}} \alpha+\beta_{o} \ln \frac{p}{p^{\star}}+\beta_{1} \ln \frac{z}{z^{\star}} \beta_{2} \ln Y
$$

En adelante, se hará referencia a las cantidades exportadas por Colombia relativas al Brasil como $\mathrm{q} / \mathrm{q}^{\star}=X R$ a los precios relativos entre ambos países a través de $\mathrm{p} / \mathrm{p}^{\star}=P R$; los costos relativos de Colombia vs Brasil, mediante $\mathrm{z} / \mathrm{z}^{\star} Z R$; mientras la demanda internacional se denominará como $Y$.

Para la competencia oligopolista con productos diferenciados, [6] tendrá los siguientes signos esperados para $\partial \mathrm{XR} / \partial \mathrm{PR}<0$; con $\partial \mathrm{XR} / \partial \mathrm{ZR}<0, \partial \mathrm{XR} / \partial \mathrm{Y} \lesseqgtr 0$. En la práctica, las cantidades relativas de las exportaciones, $\mathrm{XR}$ han afectado tanto los precios relativos, $\mathrm{PR}$, como los costos relativos $Z R$, presentándose una relación endógena.

Según lo anterior, mientras Colombia era tomador de precios en un mercado oligopólico, su estrategia competitiva se basó en ofrecer la diferenciación del café de sabor suave y expandir su producción con $\partial \mathrm{XR} / \partial \mathrm{PR}>0$. 
Los aumentos en el precio relativo del café colombiano llevaron a una mayor exportación y permitieron una creciente cuota de mercado.

Luego, cuando Colombia y Brasil se comportaron como duopolistas, la competencia se llevó a cabo ajustando las cantidades recíprocamente. Entonces Brasil como el principal productor del mundo restringió su oferta y Colombia aumentó su cuota de mercado, aunque conservando el precio relativo más alto con $\partial \mathrm{XR} / \partial \mathrm{PR}$. Las disminuciones estratégicas en el precio relativo del café colombiano, con respecto a las valorizaciones del café del Brasil, permitieron mayores exportaciones y ganancias en la cuota de mercado internacional.

Recientemente, cuando Brasil decide aumentar su oferta, Colombia estratégicamente estabiliza sus exportaciones, pareciera que, para preservar su mayor precio relativo, también con $\partial \mathrm{XR} / \partial \mathrm{PR}<0$. Entonces, aumentos en el precio relativo, vía mayor oferta del Brasil y la estabilización de la oferta de Colombia, resultaron compensadas por pérdidas en su participación sobre el mercado.

Si bien se trata de una versión del modelo de Cournot que guarda relativa coherencia con la historiografia revisada en la sección anterior y que a continuación permitió ser estimado de acuerdo con la disponibilidad de información, se trata de una simplificación que abstrae temas recurrentes y relevantes en el análisis de la historia de la competitividad del mercado cafetero como por ejemplo son la heterogeneidad de los agentes, la dinámica de la acción colectiva, y el rol de terceros competidores.

\section{Información histórica}

Para el período 1826-2018 se acopió información secundaria para Colombia y Brasil de las cantidades y precios de las exportaciones, las tasas de cambio reales y el crecimiento de la economía mundial. Hasta la mitad del siglo XIX la información histórica colombiana de las cantidades exportadas y sus precios, así como de las tasas de cambio, es fragmentaria y se completó mediante estimaciones. También fue necesario empalmar series de inflación de ambos países y la del ingreso per cápita de los Estados Unidos, es decir, darle continuidad a una serie con las variaciones de otra. Privilegiándose la disponibilidad de información que permitiera el análisis de las tendencias de largo plazo, sobre la construcción de una nuevas series históricas.

Las cantidades exportadas de Colombia para 1834, 1836-1840, 1842- 
1845, 1854-1859, 1861, 1863-1899, 1905-1960 se tomaron de Samper y Fernando (2003); 1900-1904 de Fernando Lleras citado en Junguito y Pizano (1991);1961-1997 de Junguito y Pizano (1997);1998-2018 de la Federecafé. Para 1826-1833 las cantidades exportadas se estimaron de acuerdo con los crecimientos observados en las importaciones originarias de Colombia en los anuarios de Commerce and Navigation of the United States de los años de 1826, 1828, 1830-1835. Para 1846-1853 se hizo otro tanto con las exportaciones allí reportadas por Venezuela para idéntico período. Finalmente, los años de 1835, 1841 y 1860 se estimaron según la variación entre los años vecinos. Para Brasil las cantidades exportadas entre 1826 y 1960 corresponden a Samper y Fernando (2003), y para el período 1961-2018 de Indexmundi, citando al Departamento de Agricultura de los Estados Unidos.

Los precios del café colombiano para 1826, 1828, 1830, 1833, 1834, $1837,1839,1845$ y 1848-1854 se consultaron de los anuarios de Commerce and Navigation of the United States; el período 1858-1960 corresponde a Samper y Fernando (2003); 1961-1996 a Junguito y Pizano (1997) y 1997-2018 a Federecafé. Para 1840,1841,1843, 1846 y 1847 se tomó el precio del café venezolano usando los anuarios de Commerce and Navigation of the United States. Mientras que el resto de serie se estimó de acuerdo con los crecimientos del precio promedio de las importaciones de café de los Estados Unidos en Samper y Fernando (2003). Los precios de las exportaciones del Brasil para 1826-1960 según Samper y Fernando (2003), la referencia Río 7 durante 1826-1894 y la Santos 4 para 1895-1960; esta última también fue consultada para 1961-1964 (Embajada de Brasil en Washington, 1965); en adelante el precio de la denominación brazilian naturals en la Organización Internacional del Café.

Para ambos países la serie del costo unitario de los insumos en divisas se aproximó en el índice costo de vida dividido sobre la tasa de cambio.

La serie de índices de precios de Colombia $(1900=100)$ requirió empalmar datos de varias series. Para 1826-1879 un índice de costo de vida para Bogotá, donde los años faltantes de 1836, 1867-1869 y 1875 se estimaron según crecimientos de los años vecinos (Pardo, 1972); de acuerdo con un índice de salarios del cultivo del café para 1880-1899 (Bustamante, 1973); para 1900-1904 según el índice de costo de vida elaborado por Pardo (1972); los estimativos de inflación para 1905-1954 elaborados por Grupo de Estudios del Crecimiento Económico Colombiano (GRECO, 1999); y 1955-2018 con el índice de precios al consumidor del Departamento Administrativo 
Nacional de Estadística (DANE).Aquí se obviaron consideraciones relacionadas con las canastas de bienes y sus ponderaciones (Urrutia, 2007; Mejía, 2015).

Los índices de precios de Brasil $(1900=100)$ para 1831-2010 se tomaron de la serie de CLIO INFRA y se empalmaron con la información de 2011-2018 del Banco Mundial.La información para 1826-1830 se empalmó con los índices elaborados por Lobo et al (1971, p. 260) utilizando la canasta de bienes de 1856.

La tasa de cambio frente al dólar de Colombia para 1845-1869 se consultó en Mc Greevey (1982) citando a Alejandro López; para 1870-1904 las tasas de cambio frente a la libra esterlina de Palacios (1979) multiplicadas por las tasas de cambio de la libra esterlina frente al dólar de CLIO INFRA; para 1905-1948 se tomaron las tasas de cambio del peso frente al dólar del GRECO (1999); y para 1949-2018 las del Banco de la República. Los años comprendidos entre 1826-1844 se estimaron de acuerdo con el comportamiento del dólar frente a la libra según el CLIO INFRA.

La tasa de cambio frente al dólar de Brasil empalmó las series de 18861950 de CLIO INFRA, con la de 1951-2018 del Banco Mundial; el período 1826-1885 se estimó según las variaciones de la tasa de cambio frente a la libra esterlina de CLIO INFRA. En virtud del patrón oro, la libra y el dólar mostraron relativa paridad durante el siglo XIX, exceptuando los años de la Guerra de Secesión y la Reconstrucción. Durante la primera mitad del siglo XIX Colombia tuvo una moneda no convertible internacionalmente y el comercio internacional se realizaba en divisas extranjeras (Meisel, 1990).

La demanda mundial se aproximó en el ingreso per cápita de los Estados Unidos a precios de 1990 el cual se consultó de CLIO INFRA para 18261869;1870-2008 se obtuvo del trabajo de Maddison; y 2009-2018 se empalmó con información del Banco Mundial.

Los valores resultantes corresponden a 193 años. Los precios relativos, PR, presentan la menor variabilidad, pues su desviación estándar equivale a cinco veces su valor medio. Lo contrario ocurre con las cantidades relativas exportadas por ambos países, XR, los costos relativos, ZR, y la demanda internacional,Y, donde dicha relación es cercana a la unidad (Tabla 2).

Para las exportaciones relativas de Colombia con respecto a Brasil, XR, se observó en el siglo XIX un valor promedio de 0,01 hasta 1865, después 0,03 (Gráfica 2). Durante la primera mitad del siglo pasado este indicador tiene un promedio de 0.19, con un máximo de 0.6 en la Segunda Guerra Mundial. Posteriormente y hasta 1989, XR oscila en torno a un promedio 
de 0.45. Para luego promediar un 0.67 en los 90 y registrar un récord de 1.04 en 1992. Luego se mueve en torno a un promedio de 0.35 .

Tabla 2 - Medias, desviaciones estándar y valores extremos de XR, PR, ZR y Y para 1826-2018

\begin{tabular}{c|c|c|c|c|c}
\hline Variable & Obs & Mean & Std. Dev. & Min & Max \\
\hline XR & 193 & 0.22 & 0.23 & 0.00 & 1.04 \\
\hline PR & 193 & 1.16 & 0.28 & 0.62 & 2.08 \\
\hline ZR & 193 & 113 & 132 & 0 & 624 \\
\hline Y & 193 & 9.725 & 9.284 & 1.442 & 32.977 \\
\hline
\end{tabular}

Fuente: elaboración del autor.

$\mathrm{XR}=$ exportaciones relativas $\mathrm{Col} / \mathrm{Bra} ; \mathrm{PR}=$ precios relativos $\mathrm{Col} / \mathrm{Bra} ; \mathrm{ZR}=$ costos relativos $\mathrm{Col} / \mathrm{Bra} ; \mathrm{Y}=$ ingreso per cápita de los Estados Unidos.

Hasta 1857 los precios de las exportaciones colombianas estuvieron por debajo de las exportaciones brasileñas, con un índice de precios relativos, PR, promedio de 0.85 , el cual se elevó a 1.08 en adelante. Durante la primera mitad del siglo pasado los precios relativos de las exportaciones de ambos países oscilaron en torno a 1.3, para luego promediar la unidad hasta 1989. Desde la década de los 90 el promedio se elevó a 1.5.

La trayectoria del indicador de los costos relativos de Colombia vs Brasil expresados en dólares, ZR, muestra una evolución irregular, resultado del comportamiento de los índices de precios internos y de las tasas de cambio frente al dólar. En el siglo XIX este indicador promedió 76 y 176, antes y después de 1865. Durante la primera mitad del siglo pasado ZR tiene una media de 243. Entre 1952 y 1989 un promedio de 1.7. Para finalmente tender a cero. Un resultado de la historia de la inflación y de la devaluación en ambos países, como aconteció durante la Guerra de los Mil Días en Colombia y la segunda mitad del siglo XX en Brasil.

Finalmente, la trayectoria del ingreso per cápita en los Estados Unidos muestra una tendencia creciente. Entre 1826-1865 promedió US\$1.882 y el resto del siglo XIX casi se duplicó mediando US\$3.082. Durante la primera mitad del siglo pasado este indicador nuevamente se dobló, para una media de US $\$$ 6.423. Entre 1952 y 1989 un promedio de US\$15.500, para finalmente oscilar en torno a US\$28.809. 


\section{Gráfica 2 - Cantidades exportadas y precios, costos y demanda mundial, 1826-2018}
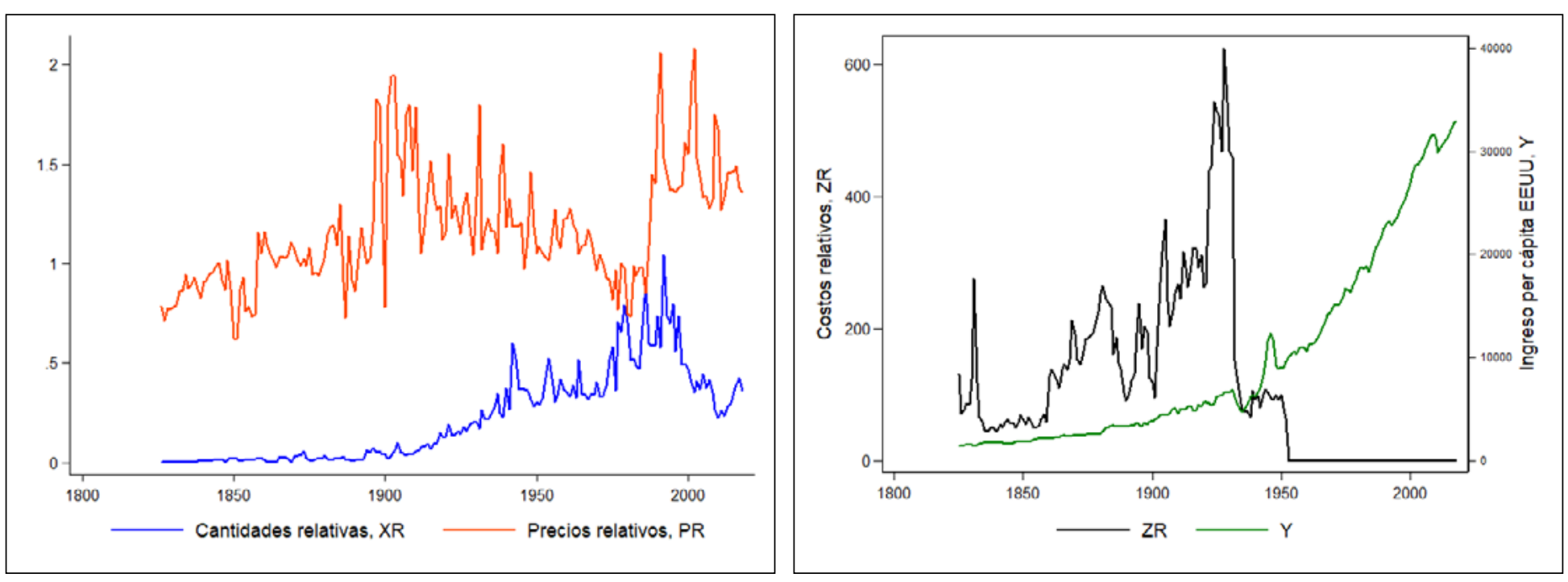

Fuente: sección 2. Elaboración del autor.

Durante 1826-2018 la correlación entre XR y PR fue de 0.21 y las cantidades colombianas crecieron anualmente al 5.5\%, es decir, más de dos veces las brasileñas y superándolas en un tercio en el crecimiento de los precios, $1 \%$ para Brasil y $1.3 \%$ para Colombia (Tabla 3 ). Sin embargo, considerando subperiodos según los cambios estructurales identificados en la sección siguiente, se presentaron modificaciones tanto en el signo de las correlaciones, como en las tasas de crecimiento de XR y PR.

Para 1826-1909, la correlación entre XR y PR habría sido del 0.58, cuando las exportaciones colombianas crecieron en cantidades desde unos valores muy bajos, al $4.2 \%$ anual y aumentaron precios relativos al $0.8 \%$. Luego en 1910-1990, se presentó una correlación negativa de 0.46 entre las exportaciones y los precios relativos de Colombia y Brasil, con un estancamiento en los precios relativos para el café colombiano y de un crecimiento $3.2 \%$ en cantidades, resultado de aumentar cantidades exportadas por Colombia al 4.1\% mientras que Brasil lo hacía al 0.8\%. En 1991-2018 la correlación prácticamente se anula, siendo igual a -0.05 , las XR de Colombia caen al $1.7 \%$, y sus precios relativos $1,5 \%$, consecuencia del estancamiento de sus cantidades, mientras Brasil crecía al 1.8\%.

En síntesis, durante el siglo XIX Colombia emergió trabajosamente en el mercado cafetero como un productor tomador de precios con una correlación positiva y crecimientos en precios y cantidades. Durante 1910-1990 
Colombia se transforma en oligopolista del café suave mediante una estrategia competitiva de ajustes en las cantidades, aumentando sostenidamente exportaciones por encima de Brasil y ajustando estratégicamente precios a ritmo parecido que su competidor.A partir de 1989 las exportaciones de Colombia pierden ritmo y mercado, como resultaría de una estrategia de valorización, pero con menores precios relativos.

Tabla 3 - Exportaciones de café colombiano y brasileño durante 1826-2018. Crecimiento anual y correlaciones

\begin{tabular}{c|c|c|c|c|c|c|c}
\hline \multirow{2}{*}{ Años } & \multicolumn{2}{|c|}{ Precios } & \multicolumn{2}{c|}{ Cantidades } & \multirow{2}{*}{ PR } & XR & $\begin{array}{c}\text { Correlación } \\
\text { XR-PR }\end{array}$ \\
\cline { 2 - 7 } & Brasil & Colombia & Brasil & Colombia & & & 0.58 \\
\hline $1826-1909$ & $-0.8 \%$ & $-0.1 \%$ & $4.9 \%$ & $9.3 \%$ & $0.8 \%$ & $4.2 \%$ & 0.46 \\
\hline $1910-1990$ & $2.3 \%$ & $2.3 \%$ & $0.8 \%$ & $4.1 \%$ & $0.0 \%$ & $3.2 \%$ & $-0.4 \%$ \\
\hline $1991-2018$ & $3.1 \%$ & $1.5 \%$ & $1.8 \%$ & $0.0 \%$ & $-1.5 \%$ & $-1.7 \%$ & -0.05 \\
\hline $1826-2018$ & $1.0 \%$ & $1.3 \%$ & $2.5 \%$ & $5.5 \%$ & $0.3 \%$ & $2.9 \%$ & 0.21 \\
\hline
\end{tabular}

Fuente: elaboración del autor.

$\mathrm{XR}=$ exportaciones relativas Colombia/Brasil; $\mathrm{PR}=$ precios relativos Colombia/Brasil.

\section{Cambio estructural y estacionariedad}

Siguiendo el modelo de Cournot el análisis de largo plazo se realizó sobre las series originales, con el propósito de estimar un modelo de cointegración considerando tanto los quiebres estructurales, como la estacionariedad. Entonces como preámbulo a la estimación econométrica, a continuación se presentan los principales resultados de las autocorrelaciones, las pruebas de raíz unitaria con y sin cambio estructural, su contraste con una prueba de cambio estructural endógena a los datos y finalmente una reflexión sobre su relación con el trabajo histórico. En el anexo se presenta detalle de la metodología seguida para analizar la estacionariedad y la estabilidad.

El análisis de cointegración requiere de la existencia de raíz unitaria en al menos una las series y que los errores de la regresión conjunta sean estacionarios. Entendida la estacionariedad como un proceso aleatorio sin termino constante, ni tendencia, ni raíz unitaria. Es decir, la variación de una variable sería una fracción de su valor rezagado, $\rho-1 \neq 0$, según $\Delta_{t}=(\rho-1) y_{t-1}+\epsilon_{t}$, permitiendo un proceso convergente (Enders, 1995). 
Por consiguiente, la exploración empírica de la estrategia competitiva de Colombia en el mercado cafetero con información bicentenaria se fundamenta en la estabilidad y estacionariedad conjunta en torno a una tendencia común de largo plazo, de las cantidades exportadas por Colombia relativas al Brasil, LXR, los precios relativos, LPR, los costos relativos, LZR y la demanda mundial, LY. Donde el prefijo L corresponde a la transformación logarítmica de las series originales.

De manera individual, LXR, LPR, LZR y LY mostraron funciones de autocorrelación serial con estabilidad en sus rezagos, mientras que las autocorrelaciones parciales, señalaron correlaciones seriales de primer orden, sugiriendo que las series no serían estacionarias, es decir que ni su valor medio, ni su variabilidad son estables en el tiempo (Anexo, Gráfica 5).Además, detrás de las correlaciones entre LXR y LZR (Anexo, Tabla) los datos aparecen en dos agrupaciones de puntos distantes, que si se aproximaran mostrarían una tendencia decreciente, sugiriendo la existencia de quiebre estructural (Anexo, Gráfica 6).

En las pruebas de raíz unitaria (Tabla 4) de Phillips y Perron (1988), sin considerar cambios estructurales, se rechazaron con un valor probabilístico menor al 5\% para la hipótesis de presencia de raíz unitaria en LXR y LPR, con valores de -4.45 y -5.66 , considerando la existencia de constante y tendencia (Anexo, ecuación 8). Sin embargo, en presencia de cambio estructural las mencionadas pruebas de raíz unitaria serían débiles para rechazar la hipótesis nula (Clemente; Montañés; Reyes, 1988).

Entonces, se consultaron los resultados de la prueba de raíz unitaria de Clemente-Montañés-Reyes, la cual es endógena a cambios estructurales de los datos, tanto si son únicos o dobles, como sin son discretos o de nivel, de manera respectiva (anexo, ecuación 9), cuyos valores revelan la presencia de raíz unitaria con un p-valor menor al 5\% para las cantidades relativas, LXR y la demanda mundial, LY, en las diferentes modalidades de cambio. Mientras que, con los precios relativos, LPR, no habría raíz unitaria considerando un solo cambio estructural y lo contrario si fuera doble. Los costos relativos, LZR, tampoco tendrían raíz unitaria considerando cambios discretos y lo contrario si fueran de nivel (Tabla 4).

Es decir, solo LXR y LPR serían estacionarias según la prueba de raíz unitaria de Philips-Perron mientras habría raíz unitaria en la mayoría de las pruebas de estacionariedad Clemente-Montañés-Reyes, CMR. 
Tabla 4 - Prueba de raíz unitaria para LXR, LPR, LZR y LY

\begin{tabular}{|c|c|c|c|c|c|c|c|c|c|}
\hline \multicolumn{2}{|c|}{$\begin{array}{c}\text { Cambio } \\
\text { estructural }\end{array}$} & \multicolumn{2}{|c|}{ LXR } & \multicolumn{2}{|c|}{ LPR } & \multicolumn{2}{|c|}{ LZR } & \multicolumn{2}{|c|}{ LY } \\
\hline \multicolumn{10}{|c|}{ Raíz unitaria de Phillips-Perron (t) } \\
\hline \multicolumn{2}{|c|}{ Ninguno } & -4.45 & $\star \star \star$ & -5.66 & $\star \star \star$ & -2.14 & & -3.4 & \\
\hline \multicolumn{10}{|c|}{ Raíz unitaria con cambio estructural de Clemente-Montañes-Reyes (t) } \\
\hline \multirow[t]{4}{*}{ Único } & Discreto & -3.34 & & -4.24 & $\star$ & -45.07 & $\star \star \star$ & -2.26 & \\
\hline & & 1908 & $\star \star \star$ & 1889 & $\star$ & 1951 & $\star \star \star$ & 1932 & $\star \star$ \\
\hline & Nivel & -3.54 & & -3.54 & $\star$ & -0.71 & & -2.16 & \\
\hline & & 1913 & $\star \star \star$ & 1893 & $\star \star \star$ & 1950 & $\star \star \star$ & 1946 & $\star \star \star$ \\
\hline \multirow[t]{6}{*}{ Doble } & Discreto & -4.3 & & -5.44 & & -54.28 & $\star \star \star$ & -2.95 & \\
\hline & & 1892 & $\star \star \star$ & 1856 & $\star \star$ & 1859 & $\star \star \star$ & 1876 & \\
\hline & & 1924 & $\star$ & 1985 & $\star \star$ & 1951 & $\star \star \star$ & 1932 & $\star \star$ \\
\hline & Nivel & -4.66 & & -4.01 & & -1.7 & & -2.49 & \\
\hline & & 1887 & $\star \star \star$ & 1898 & $\star \star \star$ & 1950 & $\star \star \star$ & 1946 & $\star \star \star$ \\
\hline & & 1922 & $\star \star \star$ & 1908 & $\star \star$ & 1954 & $\star \star \star$ & 1991 & $\star \star \star$ \\
\hline
\end{tabular}

Fuente: autor usando pperron, clemio1, clemio1, clemao2, clemao2 en stata.

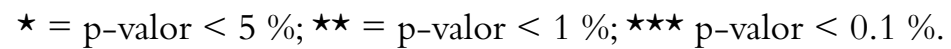

En logaritmos: $\mathrm{XR}=$ exportaciones relativas $\mathrm{Col} / \mathrm{Bra}$; $\mathrm{PR}=$ precios relativos $\mathrm{Col} / \mathrm{Bra} ; \mathrm{ZR}=$ costos relativos $\mathrm{Col} / \mathrm{Bra} ; \mathrm{Y}=$ ingreso per cápita de los Estados Unidos.

Por lo tanto, se recurrió a la identificación de cambios estructurales según la razón de verosimilitud de Quandt (Hansen 2012), la cual también es endógena a los datos y tampoco predetermina cuando sería la ocurrencia de los cambios estructurales (Anexo, ecuación 10), para posteriormente a contrastar sus resultados con las pruebas de CMR.

Para las exportaciones relativas de Colombia respecto a las de Brasil, LXR, (Gráfica 3), la prueba de Quandt identificó cambios estructurales en $1909\left(3.7^{\star}\right)$, para los precios relativos, LPR y el período $1985-1999$ con un máximo en $1986\left(13.2^{\star \star}\right)$, para los costos relativos de Colombia con respec-

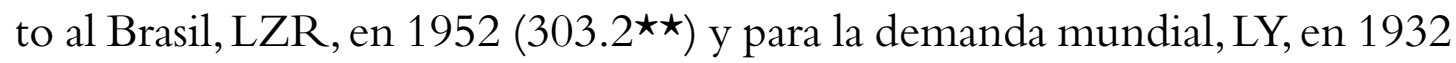
$\left(4.4^{\star}\right)$. Entre paréntesis, el valor de la prueba y los asteriscos que indican satisfactorios niveles de significancia estadística. 
Gráfica 3 - Prueba de Quandt para cambio estructural
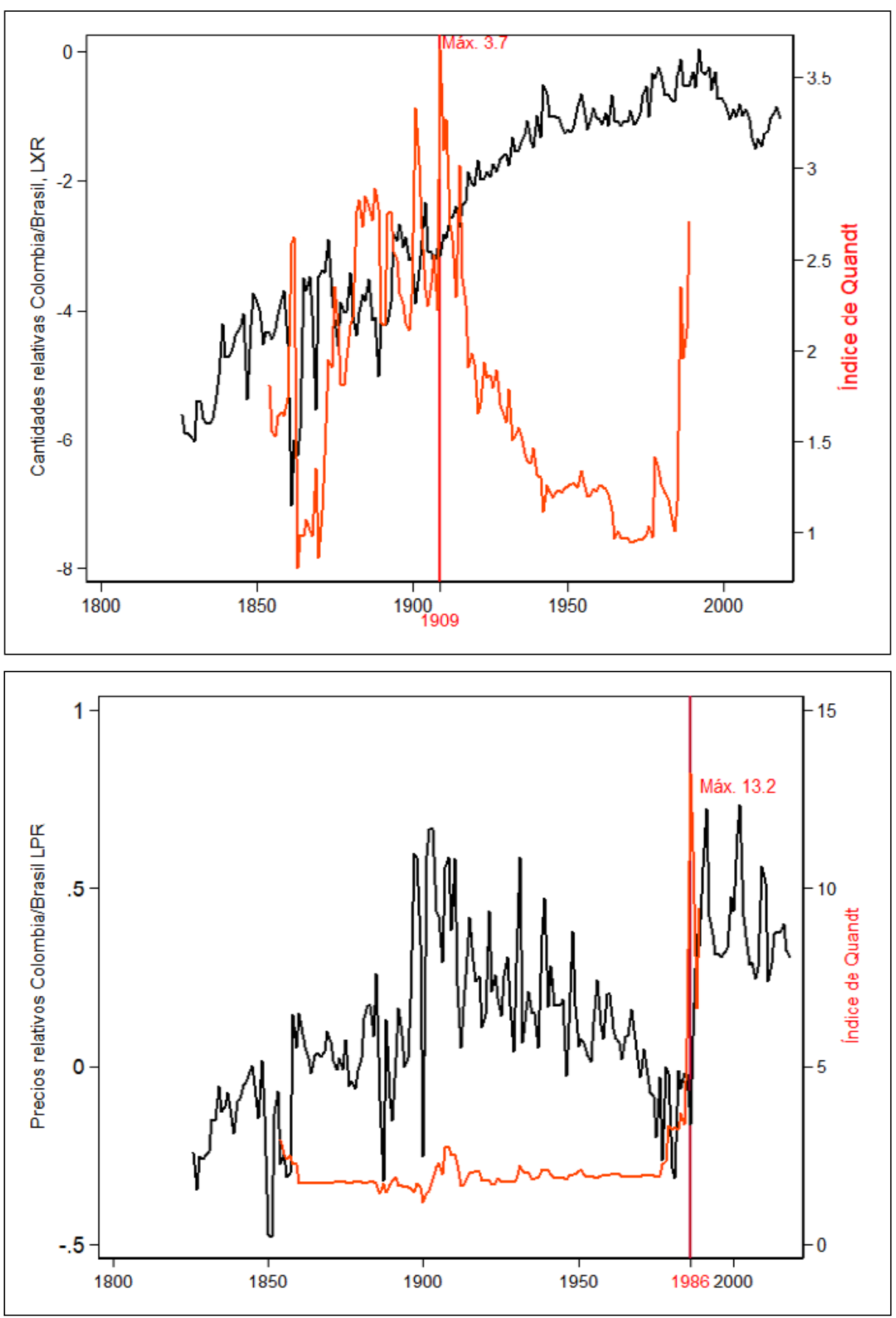

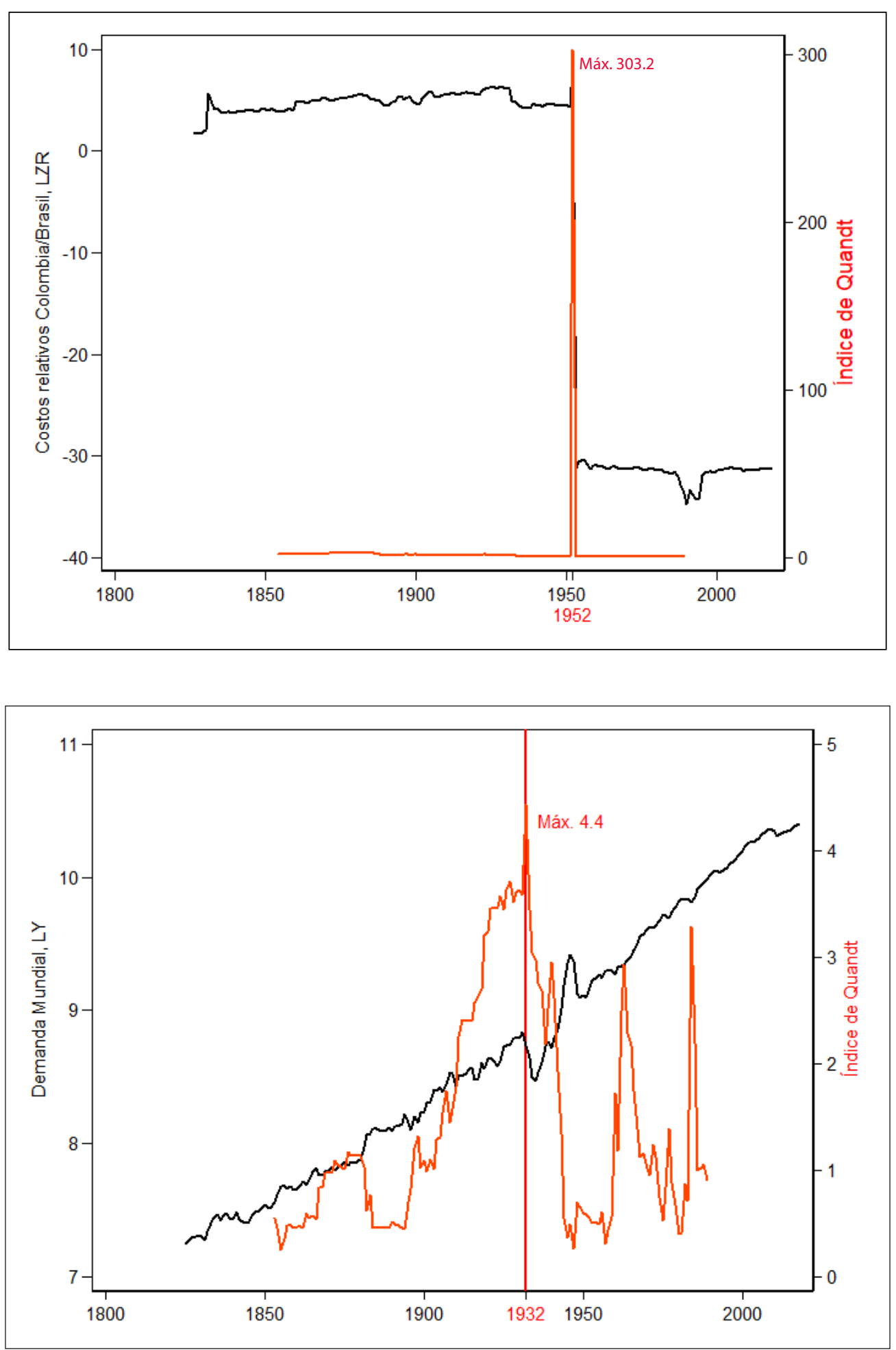

Fuente: elaboración del autor usando algoritmo para QLRT (Torres, 2016). LXR = logaritmo de las exportaciones relativas Colombia/Brasil. Con valores críticos de 3.7 y 4.5 , para valor probabilísticos menores al 5\% y $1 \%$, respectivamente. 
Aunque las pruebas de Quandt y de CMR son diferentes en sus propósitos, ambas coinciden en identificar cambios estructurales. Para las cantidades relativas, LXR, que el quiebre estructural en el año de 1909 en la prueba de Quandt es coincidente con el año 1908 reportado en la prueba CMR de raíz unitaria para cambio único y discreto (Tabla 4). Mientras que, para los precios relativos, LPR, la prueba de Quandt señala un máximo en 1986 vs 1985 para la CMR con doble cambio discreto. Para los costos relativos LZR, la primera señala un quiebre estructural en 1952 vs 1950/1951 en las diferentes pruebas CMR. Mientras con LY la coincidencia en 1932 se da con las pruebas CMR de cambio discreto.

De acuerdo con la literatura histórica reseñada la presencia de cambios estructurales en las series correspondería a transformaciones en aspectos relacionados con la estrategia competitiva de acuerdo con lo previsto por el modelo de Cournot.

La introducción de la política de valorización por parte de Brasil a comienzos del siglo pasado (Abreu; Bevilaqua, 1996) explicaría la coincidencia para 1908-1909 del quiebre estructural para las cantidades colombianas exportadas relativas a las brasileñas, marcando el comienzo del tránsito de Colombia desde tomador de precios hasta convertirse en un jugador oligopolista.

El final del Acuerdo Internacional del Café estaría tras los cambios estructurales identificados para los precios relativos de Colombia frente al Brasil, LPR, pues también significó el abandono de Brasil de su política de valorización (Bacha, 2016), a partir de allí se produciría un cambio de roles, donde Colombia estabilizó su oferta y sus precios relativos repuntaron, mientras que Brasil y otros exportadores atendieron la expansión del mercado.

Mientras que para los costos unitarios relativos, LZR, el cambio estructural observado en 1952 coincide con la implementación del sistema cambios múltiples en Brasil en 1953, el cual introdujo una devaluación real respecto a los regímenes cambiarios anteriores (Stuhlberger, 2015), pues junto al monopolio cambiario por parte del gobierno, se sumaron las devaluaciones periódicas enmarcadas en la estrategia de sustitución de importaciones, de promoción de exportaciones y la estabilización de la balanza de pagos, una política cambiaria que también fue adoptada por Colombia ajustando la devaluación según el precio internacional del café (Edwards, 1985).

El cambio estructural reportado en 1932 en la demanda mundial, LY, coincide con la caída de la economía mundial durante la Gran Depresión y la búsqueda de Brasil de una estrategia cooperativa con Colombia, para compartir 
los costos de la valorización ante la postración de las finanzas públicas, tal como se hizo evidente en 1937 con las negociones tras el fugaz pacto binacional (Bates, 1994; Robles, 2018).

Estos cambios estructurales en las tendencias de las series implicarían que su estacionariedad o relacionamiento con el tiempo, no tendrían la aleatoriedad deseada para las estimaciones que asumen estabilidad en los parámetros.

De hecho, según la prueba de nivel cuasi-local (quasi local-level qll) de estabilidad temporal de los coeficientes de la regresión (Elliot; Muller, 2006), una explicación de LXR en función de LPR, LZR y LY para 1826-2018 adolecería de inestabilidad en los parámetros, considerando un rezago en las diferencias, arrojando un valor de -24.6, rechazándose la hipótesis nula de estabilidad con un valor probabilístico inferior al 1\%. Otro tanto ocurrió para 1910-208. Mientras que lo contrario se reportó para 1826-1910 y 1991-2018.

\section{Un modelo con mínimos cuadrados ordinarios dinámico}

La relación de largo plazo de las series en escala logarítmica de las cantidades exportadas por Colombia relativas al Brasil, LXR, los precios relativos, LPR, los costos relativos, LZR y la demanda mundial, LY, en torno a una tendencia común estocástica y su endogeneidad, se estimó mediante un modelo de cointegración con mínimos cuadrados ordinarios dinámico (Stock; Watson, 2016) siguiendo a Miyasaki y Hamura (2014), Baum (2007) y Hansen (2012), así como otra literatura relevante.

La técnica de cointegración de series de tiempo utilizada privilegia el análisis de largo plazo considerado la estacionariedad, es decir, la convergencia hacia un equilibrio ante un cambio estructural o perturbación ocasionada por un evento, en este caso considerando cambios en las variables y parámetros del modelo teórico.

Para la estimación de la cointegración se utilizó un modelo de mínimos cuadrados ordinarios dinámico (MCOD), el cual adiciona diferencias adelantadas y rezagadas de las variables explicativas para corregir eventuales problemas de endogeneidad, autocorrelación y heterocedasticidad, permitiendo estimadores asintóticamente eficientes (Stock; Watson, 1993).Además, el MCOD permite la interpretación de los coeficientes como elasticidades, incorporar las endogeneidades temporales, los cambios estructurales identifi- 
cados, mediante dummies y exogeneidades al modelo relacionadas con el clima, las crisis financieras y los acuerdos comerciales.

La estimación del ajuste en las cantidades de la competencia oligopolista con productos diferenciados en el mercado cafetero internacional, mencionada en [6], correspondería a:

$$
y_{1, t}=\alpha+\beta^{\prime} y_{2, t}+y D_{t, \tau}+\omega^{\prime} D_{t, \tau} y_{2, t}+\sum_{i=-p}^{p} \theta_{i} \Delta y_{2, t-i}+u_{t}
$$

Donde $\alpha$ será el intercepto; $y_{1, t}$ representa LXR; $y_{2, t}$ es un vector que comprende LPR, LZR y LY, mientras $\beta$ es el correspondiente vector de efectos de largo plazo, expresados como elasticidades, los cuales reflejarían el cambio porcentual en LXR cuando alguna de las variables explicativas aumenta en un $1 \%$.

El coeficiente de precio relativo, LPR, tendría un signo esperado negativo (positivo) como competidor oligopolístico (tomador de precios), también en el caso de los costos relativos, LZR y al contrario con el signo de la demanda internacional LY; $D_{t, \tau}$ es una variable dicótoma del cambio estructural de nivel con valores iguales a cero si $t<\tau$, uno para el resto, considerando el cambio identificado en año $\tau$ con el índice de Quandt, así como los revelados por las pruebas de Clemente-Montañés-Reyes; también se consideraron otras dummies para los años que se reportaron alteraciones climáticas, crisis financieras y acuerdos de productores, $\gamma$ será un vector del cambio porcentual de nivel, $\delta$ un vector del cambio relacionado con la pendiente; $\theta$ es un vector de elasticidades de los $p$ adelantos y rezagos de las regresores en diferencias, $\Delta y_{2, t-1}$, los cuales capturan endogeneidades; $u$ serán los errores.

La estimación de un modelo dinámico de mínimos cuadrados ordinarios para 1826-2018 arrojó elasticidades de las exportaciones del café colombiano en proporción al brasileño, LXR, de $1,1 \%$ con respecto a los precios relativos del café colombiano sobre el brasileño, LPR; una elasticidad de - $0,2 \%$ con relación a los costos relativos entre ambos países, LZR; una elasticidad de $1,5 \%$ con respecto a la dinámica de la demanda internacional, LY, aproximada en el ingreso nacional per cápita de los Estados Unidos; también, resultó negativo el coeficiente asociado a una variable dummy de las crisis financieras internacionales (Tabla 5). 
Tabla 5 - Principales resultados de la estimación de un modelo de cointegración para las cantidades exportadas, LXR

\begin{tabular}{|c|c|c|c|c|c|c|c|c|c|c|}
\hline \multirow{2}{*}{$\begin{array}{c}\text { Explicaciones } \\
\text { delas } \\
\text { cantidades } \\
\text { relativas LXR }\end{array}$} & \multicolumn{2}{|c|}{$1826-2018$} & \multicolumn{2}{|c|}{ 1826-1909 } & \multicolumn{2}{|c|}{$1910-2018$} & \multicolumn{2}{|c|}{ 1910-1990 } & \multicolumn{2}{|c|}{ 1991-2018 } \\
\hline & Coef. & P-valor & Coef. & P-valor & Coef. & P-valor & Coef. & P-valor & Coef. & P-valor \\
\hline $\begin{array}{c}\text { Precios relativos } \\
\text { LPR }\end{array}$ & 1.09 & 0.00 & 2.03 & 0.04 & -1.17 & 0.00 & -0.86 & 0.05 & -1.12 & 0.04 \\
\hline $\begin{array}{c}\text { Costos relativos } \\
\text { LZR }\end{array}$ & -0.19 & 0.01 & & & -0.31 & 0.00 & 0.22 & 0.00 & & \\
\hline $\begin{array}{l}\text { Demanda } \\
\text { mundial LY }\end{array}$ & 1.54 & 0.00 & 1.81 & 0.00 & 0.44 & 0.00 & 0.78 & 0.00 & -3.06 & 0.00 \\
\hline $\begin{array}{c}\text { Crisis } \\
\text { financieras DC }\end{array}$ & -0.51 & 0.00 & -1.86 & 0.00 & & & & & & \\
\hline 1887 & & & -0.81 & 0.03 & & & & & & \\
\hline 1909 & 1.15 & 0.00 & & & & & & & & \\
\hline 1952 & -7.28 & 0.01 & & & -11.03 & 0.00 & -7.95 & 0.00 & & \\
\hline 1987 & -1.49 & 0.00 & & & & & & & & \\
\hline Constante & -15.35 & 0.00 & -17.78 & 0.00 & -3.62 & 0.00 & -7.19 & 0.00 & 30.78 & 0.00 \\
\hline $\begin{array}{l}\text { Avances de } \\
\text { explicativas }\end{array}$ & 1 & & 3 & & 1 & & 1 & & 1 & \\
\hline $\begin{array}{l}\text { Rezagos de } \\
\text { explicativas }\end{array}$ & 1 & & 3 & & 1 & & 1 & & 2 & \\
\hline $\mathrm{R}^{2}$ & 0.91 & & 0.42 & & 0.76 & 0.00 & 0.80 & 0.00 & 0.83 & \\
\hline Observaciones & 190 & & 77 & & 106 & & 78 & & 24 & \\
\hline $\begin{array}{c}\text { Cambio } \\
\text { estructural / } \\
\text { Chowchi }^{2}\end{array}$ & 124.92 & 0.00 & 4.88 & 0.00 & 64.05 & 0.00 & 10.99 & 0.00 & & \\
\hline $\begin{array}{c}\text { Raíz unitaria/ } \\
\text { Phillips-Perron } \\
\text { Z(t) }\end{array}$ & -7.73 & 0.00 & -7.07 & 0.00 & -4.96 & 0.04 & -4.67 & 0.00 & -2.29 & 0.17 \\
\hline $\begin{array}{c}\text { Asimetría y } \\
\text { curtosis/ } \\
\text { D’Agostino et } \\
\text { al. chi }{ }^{2}\end{array}$ & 5.59 & 0.06 & 10.62 & 0.00 & 6.47 & 0.04 & 6.29 & 0.04 & 1.27 & 0.53 \\
\hline
\end{tabular}

Fuente: autor usando cointreg, varsoc, vecrank, test, sktest en stata.

En logaritmos: $\mathrm{XR}=$ exportaciones relativas $\mathrm{Col} / \mathrm{Bra}$; $\mathrm{PR}=$ precios relativos $\mathrm{Col} / \mathrm{Bra} ; \mathrm{ZR}=$ costos relativos Col/Bra; $\mathrm{Y}$ = ingreso per cápita de los Estados Unidos; 1987, 1909, 1952 y 1987 dummies de cambio de nivel. 
La inclusión de variables dicótomas para 1909, 1952 y 1987 resultaron estadísticamente significativas. La primera indicando un cambio positivo de nivel a comienzos del siglo pasado en LXR, coincidiendo con la introducción de la política de valorización del café brasileño. La dummy correspondiente al cambio estructural de 1952 en los costos relativos, resultó negativa indicando un cambio de nivel hacia la baja coincidiendo con la introducción del sistema de cambios múltiples en el Brasil. Otro tanto aconteció, con la dummy de 1987 en la víspera de la ruptura del Acuerdo Internacional del Café. La prueba de Chow de cambio estructural para estas dummies arrojó un $\chi^{2}(3)$ de 125 con un valor probabilístico inferior al $1 \%$.

Las estimaciones de este modelo mostraron satisfactorios resultados en las pruebas de estacionariedad y normalidad. La prueba de raíz unitaria de Phillips-Perron aplicada a los errores del modelo arrojó un valor de -7.7 con un p-valor menor a $1 \%$, sugiriendo que los errores serían estacionarios. Mientras que la prueba conjunta de asimetría y curtosis arrojó una $\chi^{2}(2)=$ 5.6 según la cual se podría rechazar la hipótesis nula de normalidad en los errores.

La elasticidad positiva de LXR a LPR estaría dando alcance a lo ya observado en las tasas de crecimiento y correlaciones de 1826-1909 y 19882018 (Tabla 3), sin embargo, obviaría que Colombia habría ajustado sus exportaciones inversamente a los precios relativos, para ganarle mercado a Brasil y beneficiarse de su política de valorización, tal como ocurrió entre 1909 y 1987. Por consiguiente, se procedió a estimar el modelo en dos subperiodos considerando el cambio estructural en LXR acaecido en 1909, de acuerdo con el índice de Quandt.

Allí el contraste entre los modelos para 1826-1909 y 1910-2018 reveló que la elasticidad con respecto a los precios relativos LPR, pasaba de 2 a -1.2 , lo cual correspondería al tránsito de la estrategia de tomador de precios hacia la competencia olipolística con ajustes en las cantidades exportadas. La elasticidad referente a los costos relativos LZR no fue significativa para el primer período, pero posteriormente arrojó un valor de -0.3 para 1910-2018, atribuible al desarrollo de los mercados internos de factores y la monetización, así como por la mejor calidad de la información; la elasticidad a la demanda en ambos períodos resultó positiva, pasando de 1.8 a 0.4 , lo cual correspondería a la diversificación del mercado internacional y su diferenciación.

Para 1826-1909 también resultó significativa la dummy del cambio estructural en 1887 identificada por la prueba de raíz unitaria de doble nivel 
y cambio estructural (Tabla 4), debido al rebote de la exportación del Brasil luego de ese año, y las otras tres de acuerdo con el índice QLRT. Otro tanto aconteció con la elasticidad a las crisis financieras internacionales.

Durante 1910-2018 también resultaron significativas los costos relativos LZR y el cambio estructural acaecido en 1952. En cambio, no resultó significativa la dummy relacionada con los acuerdos entre países productores, las cuales correspondían a 34 años de los 80 que comprendió este período. Esto sumado a la elasticidad negativa con los precios relativos, reflejaría que la competencia no cooperativa prevaleció y daría alcance a las referencias en la literatura a las prácticas de evasión de los acuerdos.

Adicionalmente, se procedió a estimar el modelo en dos subperiodos considerando el cambio estructural en LXR acaecido en 1990, de acuerdo con el índice QLRT y coincidente con la ruptura del Acuerdo Internacional de Café. Aunque 1991-2018 es el más reciente período sería el más corto de todos y con menor disponibilidad de información para un análisis de cointegración.

El contraste de resultados de los modelos para 1910-1990 y 1991-2018 reveló que la elasticidad con respecto a los precios relativos LPR, pasaba de -0.9 a -1.1 , y de esta manera habría prevalecido la rivalidad estratégica entre Colombia y Brasil ajustando cantidades, pero recientemente cambiando roles, el primero estabilizó su oferta y el segundo la expandió.

La elasticidad referente a los costos relativos LZR arrojó un valor de -0.22 para 1910-1990 y luego no fue significativa, al parecer por la convergencia macroeconómica y la transformación productiva de la caficultura en Brasil. La elasticidad a la economía internacional pasó de ser positiva a negativa, de 0.8 a -3.1 , sugiriendo que las exportaciones relativas de Colombia evolucionaron en contravía de los cambios en la demanda internacional y en la diferenciación de la producción.

La adopción efectiva por Colombia de la política de valorización no habría sido inmediata a la ruptura del AIC, sino a partir del presente siglo. Así lo sugerirían el contraste de las exportaciones relativas observadas durante el período 1988-2018, con respecto a la proyección de este período de acuerdo con los coeficientes estimados por el modelo para 1910-1990 (Gráfica 4).

De acuerdo con el escenario contrafactual, a partir del 2002 Colombia comenzó a exportar dos quintas partes de las cantidades que hubiera exportado sin cambio estructural. Un orden de magnitudes que llama la atención 
sobre los resultados y alcances de la estrategia comercial, ante la inflexibilidad de la oferta y las transformaciones del mercado internacional.

\section{Gráfica 4 - Exportaciones relativas de Colombia y Brasil para $1988-2018$, observadas y proyectadas}

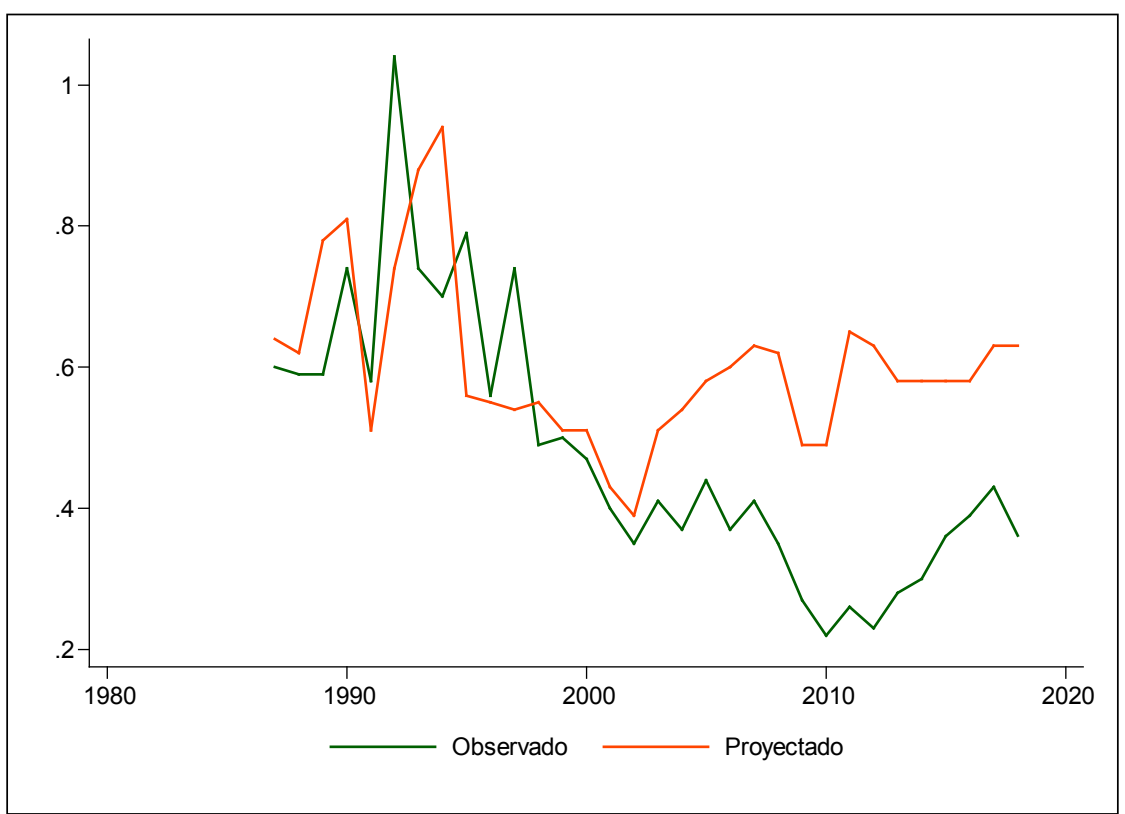

Fuente: elaboración según tabla 5 y Federecafé.

\section{Conclusiones}

Colombia completó dos siglos incursionando en el mercado mundial cafetero. Durante el siglo XIX como un productor incipiente de café suave, pero cuando Brasil implementó su política de valorización a través de la retención de sus exportaciones, el café de Colombia se tornó en oligopolista y comenzó a ganar participación en el mercado hasta sumarse a Brasil en el Acuerdo Internacional del Café. Con el retorno al libre mercado se dio un cambio de roles, Colombia privilegió la estabilización y valorización de su producción, mientras que Brasil, amplió exportaciones, mejoró la calidad y ganó participación de mercado, al igual que otros competidores.

Evidencia de lo anterior, fue recabada en la literatura y la información disponible, desde la perspectiva de la política comercial estratégica, una rama de la teoría del comercio internacional que analiza las estrategias competitivas en mercados de exportación con estructuras oligopólicas y productos diferenciados. En este caso, los dos principales exportadores privilegiaron los ajustes 
en las cantidades desde el siglo pasado, en un juego competitivo donde cada uno conocía la función de producción del rival y ajustaba su oferta según su mejor opción estratégica.

Aquí el análisis de series de tiempo se encuentra fundamentado sobre las regularidades estadísticas en torno a equilibrios de largo plazo, tal como correspondería a un bicentenario de las exportaciones de Brasil y Colombia en el mercado cafetero desde el punto de vista de la teoría de la política comercial estratégica. De esta manera fue posible explorar de manera sistemática tendencias, inercias y cambios estructurales de acuerdo con una teoría económica y enriquecer las posibilidades del análisis histórico. Se trata de un aproximación simplificada, exploratoria y probabilística construida sobre supuestos y estimaciones.

En este caso se optimizó la disponibilidad de información con procedimientos sencillos, para disponer de series de tiempo que permitieran aprovechar los recientes desarrollos de la econometría y analizar la correspondencia de sus resultados con la historiografía y la teoría. El riesgo de la discrecionalidad en la especificación de la modelación econométrica se mitigó condicionándola a la identificación de los quiebres estructurales y al contraste de la estabilidad por subperíodos, siguiendo las pruebas de estacionariedad y de estabilidad, ambas endógenas a los datos. Así como de pruebas de estabilidad en los parámetros. Dicha información se valoró de acuerdo con su relacionamiento con lo previsto por el modelo de Cournot y con la historiografia revisada.

Así, la identificación de cambios estructurales para las cantidades exportadas de Colombia con respecto a Brasil, coincidió con el comienzo de la política de valorización de Brasil en 1909, para los precios relativos ocurre lo mismo con la agonía del Acuerdo Internacional del Café por 1986, para los costos relativos el cambio estructural se da con la implementación del sistema cambios múltiples en Brasil en 1952 y para la demanda mundial con la Gran Depresión de 1932.

Por consiguiente, se procedió a estimar la relación de largo plazo, como la cointegración entre las cantidades exportadas de Colombia frente a Brasil, LXR, usando un modelo de mínimos cuadrados ordinarios dinámico. Los resultados permitieron observar cambios en la elasticidad con respecto a los precios relativos, de 1.1 a -1.2 cuando se contrastaban los períodos 1826-1909 y 1910-2018, sugiriendo el tránsito de la estrategia de tomador de precios hacia la competencia oligopolística con ajustes en las cantidades. Además, la 
elasticidad a los costos relativos fue significativa para el segundo período y con un valor de -0.3 , atribuible al desarrollo de los mercados internos de factores y la monetización.

La elasticidad a la demanda internacional resultó positiva, pasando de 1.8 a 0.4, lo cual reflejaría la diversificación y diferenciación del mercado. Las crisis financieras internacionales resultaron significativas para el primer período, al igual que los cambios estructurales en 1887, 1909, 1952 y 1987, las cuales coinciden con una helada del Brasil y con hitos en la política comercial, como fueron la valorización, el sistema tasas de cambio múltiples en Brasil y el final del Acuerdo Internacional del Café. Las dummies de los acuerdos entre países productores no fueron significativas a pesar de que casi cubrieron la mitad del segundo período, lo cual, sumado a la elasticidad negativa con los precios relativos, indicaría que la competencia no cooperativa prevaleció dando alcance a las referencias en la literatura de triangulación, evasión e incumplimientos que tuvo el AIC.

Mientras que el contraste entre 1910-1990 y 1991-2018 reveló que la elasticidad con respecto a los precios relativos se mantuvo negativa y habría predominado la rivalidad estratégica ajustando cantidades, aunque con intercambio de roles en el segundo período: Brasil expandió su oferta y Colombia la estabilizó. Igualmente, ocurrió con la elasticidad a los costos relativos, reflejando la transformación productiva de la caficultura en Brasil. Por el contrario, la elasticidad a la demanda se tornó negativa, sugiriendo que las exportaciones de Colombia evolucionaron en contravía de las tendencias del mercado.

A partir del presente siglo y de acuerdo con la evidencia aquí recabada, Colombia habría adoptado la política de valorización, tal como lo sugeriría el contraste de las exportaciones relativas observadas durante el período 19882018, con respecto a su proyección según los coeficientes estimados por el modelo para 1910-1990. Según este escenario contrafactual, a partir de 2002 se habría exportado dos quintas partes de lo esperado. Un orden de magnitudes que llama la atención sobre los resultados y alcances de la política comercial, particularmente con respecto a la inflexibilidad de la oferta a las transformaciones del mercado, entre otros aspectos. Un trago amargo para el principal productor de café suave del mundo y por el momento el epílogo de una historia inacabada sobre la construcción y sostenibilidad de la competitividad. 


\section{Bibliografia}

ABREU, M.; BEVILAQUA, A. Brazil as an Export Economy, 1880-1930. Disponible en https://ssrn.com/abstract $=37857$. Consultado el 15 de agosto de 2020 .

BACHA, E. L.; BONELLI, R. Accounting for Brazil's growth experience: 1940-2002. Discussion Paper, n. 128, 2016.

BAUM, C. Tests for stationarity and stability in time-series data. Boston College and DIW Berlin, 2009. Disponible en http://fmwww.bc.edu/cfb/stata/TStalkJan2009.beamer.pdf. Consultado el 28 de abril de 2020.

BER GQUIST, C. Café y conflicto en Colombia, 1886-1910: la Guerra de los Mil Días, sus antecedentes y consecuencias. Bogotá: Editores Banco de la Republica; El Ancora Editores, 1999.

BEYER, R. C. The marketing history of the colombian coffee. Agricultural History, v. 23, n. 4, p. 279-285, 1949.

BATES, R. La economía política del café colombiano en los años treinta: el ejercicio del poder público y la defensa de los intereses privados. Ensayos sobre Economía Cafetera, n. 10, año 7, p. 9-28, 1994.

BOHMAN, M.; JARVIS, L. The international coffee agreement: economics of the nonmember market. European Review of Agricultural Economics, v. 17, issue 1, p. 99-118, 1990.

BRANDER, J. Strategic trade policy. NBER Working Paper, n. 5020, 1995

BUSTAMANTE, D. Efectos económicos del papel moneda durante la regeneración. 1973. Disponible en http://www.cid.unal.edu.co/cidactual/index.php?option $=$ com_publicaciones $\&$ op $=$ view $\&$ Itemid $=417 \&$ adressid $=803$. Consulta do el 8 de abril de 2019.

CANO, C. G. et al. El mercado mundial del café y su impacto en Colombia. Borradores de Economía, n. 710, 2012. Disponible en http://www.banrep.gov. co/es/borrador-710. Consultado el 28 de abril de 2019. 
CARTER, C.; MACLAREN, D. Price or quantity competition? Oligopolistic structures in international commodity market. Review of International Economics, v. 5, n. 3, p. 373-85, 1997.

CARREÑO, C. I. Redes sociales durante la economía cafetera: el caso de las haciendas Bebedouro (Brasil) y La Luisiana (Colombia), 1870-1920. São Paulo: UNESP, 2015 (Tesis de Doctorado en Historia de la UNESP).

CLEMENTE, J.; MONTAÑÉS, A.; REYES, M. Testing for a unit root in variables with a double change in the mean. Economics Letters, v. 59, p. 175$182,1998$.

DE LIMA, A. La experiencia del Brasil. MISIÓN ESTUDIOS COMPETITIVIDAD CAFICULTURA EN COLOMBIA. Ponencia presentada en la Universidad del Rosario. Rosario: Universidad del Rosario, 2014.Disponible en https://www.urosario.edu.co/Home/Principal/noticias/Mision-Estudios-Competitividad-Caficultura-en-Colo/? _ga $=2$. 102618113.1272224079.1558390511-1737934937.1558390511. Consultado en abril 15 de 2019.

DURAN, J. Estado general de todo el Virreynato de Santafé de Bogotá en el presente año de 1794. Bogotá: Banco de la República; Biblioteca Luis Ángel Arango, 1794.

EDWARDS, S. Commodity export prices and the real exchange rate in developing countries: coffee in Colombia. NBER Working Paper, v. 1, n. 1570, 1985.

ELLIOT, G.; MÜLLER, U. Efficient tests for general persistent time variation in regression coefficients. Review of Economic Studies, v. 73, p. 907-940, 2016.

ENDERS, W. Applied econometric time series. Wiley series in probability and mathematical statistics. 1995.

FEDERACION NACIONAL DE CAFETEROS. Gestión integral hacia la calidad, por una caficultura organizada y mundialmente competitiva. Revista Cafetera de Colombia. v. 46, n. 207, p. 17-34, 1997. 
FEDERACION NACIONAL DE CAFETEROS. Manual del cafetero colombiano. Bogotá: Editorial Argra Ltda., 1958.

EMBAJADA DE BRASIL EN WASHINGTON. Survey of the brazilian economy. Washington, D. C., 1965.

GRUPO DE ESTUDIOS DE CRECIMIENTO ECONÓMICO COLOMBIANO (GRECO). El desempeño macroeconómico colombiano. Series estadísticas (1905-1997). Borradores de Economía, n. 121, 1999. Disponible en http://www.banrep.gov.co/es/borrador121. Consultado en abril 14 de 2019.

HANSEN, B. Advanced time series and forecasting lecture 5: structural breaks. Summer Schoo 1 in Economics and Econometrics University of Crete, 2012. Disponible en https://www.ssc.wisc.edu/ bhansen/crete/crete5.pdf. Consultado el 18 de abril de 2019.

JUNGUITO, R. Economía cafetera colombiana. Bogotá: Fedesarrollo; Fondo Cultural Cafetero, 1979.

JUNGUITO, R.; PIZANO, D. Instituciones e instrumentos de la política Económica Cafetera 1927-1997. Bogotá: Fondo Cultural Cafetero; Fedesarrollo, 1997.

JUNGUITO, R.; PIZANO, D. Producción de café en Colombia. Bogotá: Fondo Cultural Cafetero; Fedesarrollo, 1991.

LOBO, E. M. L. et al. Evolución de precios y nivel de vida en Río de Janeiro, 1820-1930: resultados preliminares. Revista Brasileira de Economia, v. 25, n. 4, p. 235-266, 1971.

MASON, K. The birth of the coffee nation: coffee in U.S. history since the revolutionary war. In: MEREWITZ, Matt; PHAM, Long; SOLURI, John. The coffee report: can fair trade solve the coffee crisis? 2004. Disponible en https:// www.cmu.edu/dietrich/ehpp/documents/2004-the-coffee-report.pdf. Consultado el 18 de abril de 2019. 
MC GREEVEY,W. Historia económica de Colombia 1845-1930. Bogotá: Editorial Tercer Mundo, 1982.

MEISEL, A. El patrón metálico 1821-1879. In: MEISEL, A. El Banco de la República: antecedentes, evolución y estructura. Bogotá: Fedesarrollo; Tercer Mundo, 1990.

MEJÍA, J. Reconstrucción de PIB regionales en Colombia (1800-2015): una revisión crítica de las fuentes y los métodos. Sociedad y economía, n. 30, p. 305-334, 2016.

MIYAZAKI, T.; HAMORI, S. Cointegration with regime shift between gold and financial variables. International Journal of Financial Research, v. 5, n. 4, 2014.

OCAMPO,J.A. El mercado mundial del café y el surgimiento de Colombia como país cafetero. Revista Desarrollo y Sociedad, n. 5, p. 127-156, 1981.

OCAMPO, J.A. La consolidación de la industria cafetera: 1930-1958. In:TIRADO, Alvaro (Org.). Nueva historia de Colombia. Bogotá: Planeta Colombiana Editorial, p. 233-262, 1989.

PALACIOS, M. El Café en Colombia (1850-1970) una historia económica, social y política. Bogotá: Editorial Presencia, 1979.

PALACIOS, M.; SAFFORD, F. Historia de Colombia: país fragmentado, sociedad dividida. Bogotá: Editorial Norma, 2002.

PARDO, A. Geografía económica y humana de Colombia. Bogotá:Tercer Mundo. Bogotá, 1972.

PELUPESSY, W. The world behind the world coffee market. Études rurales, n. 180, 2007.

PHILLIPS, P.; PERRON, P. Testing for a unit root in time series regression. Biometrika, v. 75, p. 335-346, 1988. 
RENDÓN, A. Diferenciación oligopólica del café verde colombiano en el mercado estadounidense. Ecos de Economía, v. 17, n. 36, p. 99-135, 2013

ROBLES, C. ¿Coludir o no? Las negociaciones entre Brasil y Colombia para limitar la oferta de café en la década del 1930. Documentos CEDE, n. 2, 2018. Disponible en http://economia.uniandes.edu.co/publicaciones/dcede2018-02. pdf. Consultado el 18 de agosto de 2020.

ROCHA, R.; PERILLA, J. R.; LÓPEZ, R. Una aproximación de la política comercial estratégica para el ingreso de Colombia al ALCA. Revista Desarrollo y Sociedad, n. 53, p. 45-82, 2004.

ROCHA, R. Informalidad laboral cafetera: rasgos, determinantes y propuestas de política. Archivos de Economía, n. 418, 2014. Disponible en https://colaboracion.dnp.gov.co/CDT/Estudios\%20Econmicos/418.pdf. Consultado el 9 de diciembre de 2020.

SAMPER, M. The historical construction of quality and competitiveness. In: GERVASE, William; TOPIK, Steven (Org.). The global coffee economy in Asia, Africa, and Latin America, 1500-1989. Cambridge University Press, p. 120$153,2003$.

SAMPER, M.; FERNANDO, R. Appendix historical statistics of coffee production and trade from 1700 to 1960. In: GERVASE, William;TOPIK, Steven (Org.). The global coffee economy in Asia, Africa and Latin America, 1500-1989. Cambridge University Press, p. 411-462, 2003.

SANTOS, J. From valorization to the coffee trade agreement: coffee price controls 1905-2001. In: MEREWITZ, Matt; PHAM, Long; SOLURI, John (Org.). The coffee report: can fair trade solve the coffee crisis? 2004. Disponible en https://www.cmu.edu/dietrich/ehpp/documents/2004-the-coffee-report. pdf. Consultado el 18 de abril de 2019

SECRETARY OF TREASURY. The commerce and navigation of the United States, during the year ending in the $30^{\text {th }}$ day of september, 1826. Washington, D. C.: Gales \& Seaton, 1827. Disponible en https://babel.hathitrust.org/cgi/pt?i$\mathrm{d}=\mathrm{uc1} .31175030096815 ; \mathrm{view}=1 \mathrm{up} ; \mathrm{seq}=61$. Consultado en abril 8 de 2019. 
SILBERLING, N. British Financial Experience 1790-1830. The Review of Economics and Statistics, v. 1, n. 4, p. 282-297, 1919.

STEINER, R.; SALAZAR, N.; BECERRA,A. La política de precios del café en Colombia. Bogotá: Fedesarrollo, 2015. Disponible en https://www.repository. fedesarrollo.org.co/bitstream/handle/11445/2387/Report_Febrero_2015_ Steiner_Salazar_y_Becerra.pdf?sequence $=1$ \&isAllowed=y. Consultado el 16 de agosto de 2020.

STOCK, J.; WATSON, M. Introducción a la Econometría. Madrid: Pearson Eduación, 2012.

STUHLBERGER, B. The neutrality of multiple exchange rates: industrial distortions in Brazil, 1953-1961. XI CONGRESO BRASILEÑO DE HISTORIA ECONÓMICA, 2015,Vitória. Disponible en: http://www.abphe. org.br/arquivos/2015_bernardo_wjuniski_the-neutrality-of-multiple-exchange-rates-industrial-distortions-in-brazil-1953_1961.pdf. Consultado el 20 de abril de 2019.

TOPIK, S. The integration of the world coffee market. In: GERVASE, William; TOPIK, Steven (Org.). The global coffee economy in Asia, Africa and Latin America, 1500-1989. Cambridge University, p. 21-49, 2003.

TREMBLAY, V.; HORTON, C. New Perspectives on Industrial Organization. Springer Texts in Business and Economics. Springer, New York, NY, 2012.

TORRES, O. Time series 1.5.2016. Disponible en https://www.princeton. edu/ otorres/TS101.pdf. Consultado el 28 de abril de 2019.

URRUTIA, M. Precios y salarios urbanos en el siglo XIX. Documento CEDE, n. 25, 2007. Disponible en https://economia.uniandes.edu.co/components/ com_booklibrary/ebooks/documentocede2007-25.pdf. Consultado el 8 de abril de 2019. 


\section{Anexo de la metodología sobre estacionariedad y estabilidad}

De manera individual, las series en escala logarítmica de las cantidades exportadas por Colombia relativas al Brasil, LXR, los precios relativos, LPR, los costos relativos, LZR y la demanda mundial, LY, mostraron funciones de autocorrelación serial con estabilidad en sus rezagos, mientras que las autocorrelaciones parciales, señalaron correlaciones seriales de primer orden, sugiriendo que las series no serían estacionarias (Gráfica 5).

\section{Gráfica 5 - Funciones de autocorrelación y parcial de LXR, LPR, LZR y LY}

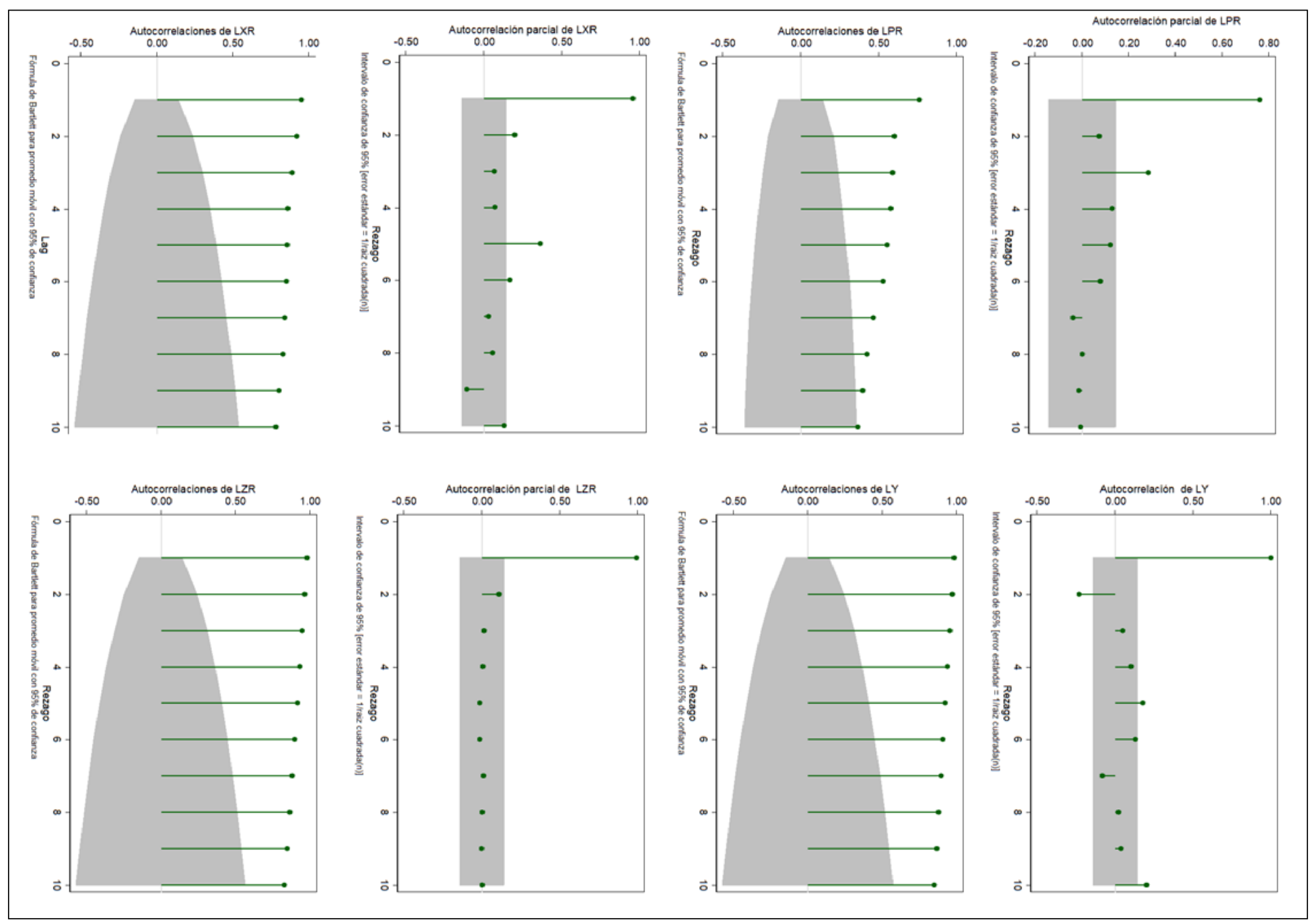

Fuente: elaboración del autor.

En logaritmos: $\mathrm{XR}=$ exportaciones relativas $\mathrm{Col} / \mathrm{Bra} ; \mathrm{PR}=$ precios relativos $\mathrm{Col} / \mathrm{Bra} ; \mathrm{ZR}=$ costos relativos $\mathrm{Col} / \mathrm{Bra} ; \mathrm{Y}=$ ingreso per cápita de los Estados Unidos 
Tabla 6 - Correlaciones entre LXR, LPR, LZR y LY, 1826-2018

\begin{tabular}{c|r|r|r|c}
\hline & LXR & LPR & LZR & LY \\
\hline LXR & 1 & & & \\
\hline LPR & 0.42 & 1 & & \\
\hline LZR & -0.68 & -0.19 & 1 & \\
\hline LY & 0.89 & 0.48 & -0.84 & 1 \\
\hline
\end{tabular}

Fuente: sección 3. Elaboración del autor.

En logaritmos: $\mathrm{XR}=$ exportaciones relativas $\mathrm{Col} / \mathrm{Bra}$; $\mathrm{PR}=$ precios relativos $\mathrm{Col} / \mathrm{Bra} ; \mathrm{ZR}=$ costos relativos $\mathrm{Col} / \mathrm{Bra} ; \mathrm{Y}=$ ingreso per cápita de los Estados Unidos.

Para el período 1826-2018 la correlación de las cantidades exportadas de café de Colombia vs Brasil, LXR, con respecto al precio relativo de ambos países, LPR, fue de 0.42 ; la correlación entre LXR y el ingreso per cápita de los Estados Unidos, Y, fue de 0.89; mientras que la correlación de LXR con los costos relativos de Colombia y Brasil, LZR, fue de -0.68 (Tabla 6). Esta última variable estaba negativamente correlacionada $(-0,19)$ con LPR y con LY (-0.84). por el contrario, LY y LPR están positivamente correlacionados $(0.48)$.

Estas correlaciones se aprecian con más detalle en las gráficas cruzadas entre los valores de LXR con LPR, LZR y LY (Gráfica 6). Los datos de LXR y LZR aparecen en dos agrupaciones de puntos distantes, que si se aproximaran mostrarían una tendencia decreciente, sugiriendo la existencia de quiebre estructural. Por el contrario, LXR y LY ofrecen claramente una tendencia creciente. Otro tanto acontece con LXR y LPR, pero en medio de una gran dispersión.

\section{Gráfica 6 - Relación de LXR con LPR, LZR y LY, 1826-2018}
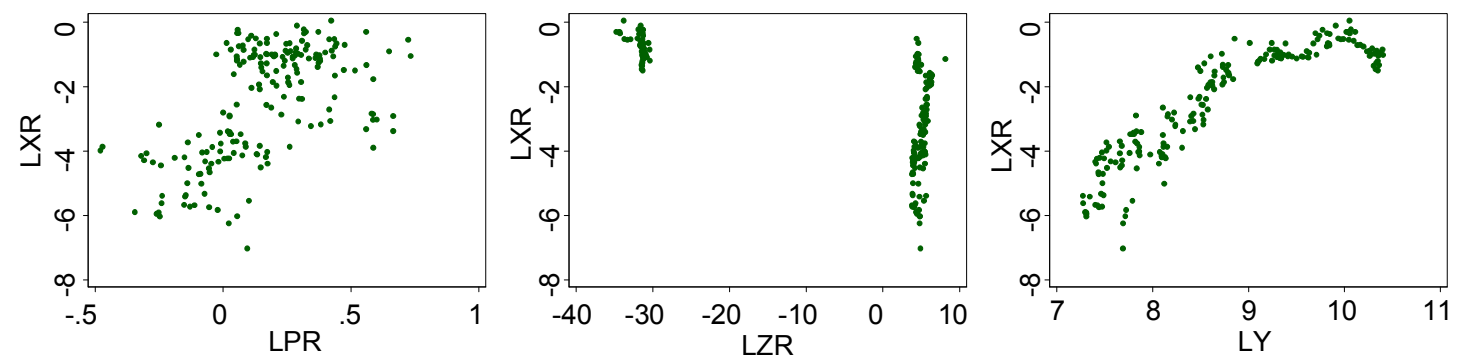

Fuente: sección 3. Elaboración del autor.

En logaritmos: $\mathrm{XR}=$ exportaciones relativas $\mathrm{Col} / \mathrm{Bra} ; \mathrm{PR}=$ precios relativos $\mathrm{Col} / \mathrm{Bra} ; \mathrm{ZR}=$ costos relativos $\mathrm{Col} / \mathrm{Bra} ; \mathrm{Y}=$ ingreso per cápita de los Estados Unidos. 
De acuerdo con la ecuación [8] la prueba de Phillips y Perron (1988) verifica la hipótesis nula de existencia de raíz unitaria con $\rho=0$, el parámetro asociado a en la explicación de $y_{t}$, considerando un intercepto $\alpha$, una tendencia $\delta$ asociada al tiempo y aplicando a los errores una corrección de la autocorrelación (Newey; West, 1987).

$$
y_{t}=\alpha+\rho y_{t-1}+\delta t+e_{t}, t=1, \ldots, n
$$

Los resultados de esta prueba rechazaron con un valor probabilístico menor al 5\%, la hipótesis de presencia de raíz unitaria en LXR y LPR, con valores de -4.45 y -5.66 , considerando la existencia de constante y tendencia (Tabla 4), habiendo corregido por autocorrelación y heterocedasticidad, mientras que lo contrario acontecería con LZR y LY, con valores de -2.14 y -3.4. Si las series se transforman en su primera diferencia las pruebas rechazarían la hipótesis nula de raíz unitaria, es decir, se reportarían como estacionarias.

Sin embargo, en presencia de cambio estructural las mencionadas pruebas de raíz unitaria serían débiles para rechazar la hipótesis nula (Clemente et al, 1988). Por consiguiente se procedió a implementar la prueba de Clemente-Montañés-Reyes, endógena a la identificación de cambio estructural, según [9], donde $\alpha$ será el intercepto; $D I_{t, \tau}$ es una variable dicótoma que corresponde al año del cambio estructural, con valor de 1 si $\mathrm{t}=\tau d$ y de lo contrario cero, siendo $\tau$ un parámetro que expresa el año en términos relativos a la duración del período de análisis $d ; D_{t, \tau}$ es otra variable dicótoma con valores iguales a cero si $t<\tau d$, y uno para el resto; $\zeta$ y $\omega$ serán los parámetros de cambio discreto y del cambio de nivel de la variable; ; $p$ representa el orden de los rezagos de las diferencias de $\Delta y_{t-1}$, mientras que $u$ serán los errores. Donde el valor ínfimo de la prueba Dickey-Fuller aumentada (Enders, 1995) de raíz unitaria $\mathrm{DF}_{t}^{*}=\inf _{\tau \in \mathrm{T}} \mathrm{DF}_{t}(\tau)$, identificará el período $\tau$ donde habría quiebre estructural.

$$
y_{t}=\alpha+\rho y_{t-1}+\zeta D I_{t, \tau}+\omega^{\prime} D_{t, \tau}+\sum_{i=1}^{p} \theta_{i} \Delta y_{t-1}+e_{t}
$$

Los resultados de la prueba de Clemente-Montañés-Réyes (1998) revelan la presencia de raíz unitaria para las cantidades relativas, LXR y la demanda mundial, LY, tanto si el cambio es único o doble, como si es un cambio discreto o de nivel. Mientras que, con los precios relativos, LPR no 
habría raíz unitaria considerando un solo cambio estructural y lo contrario si fuera doble. Los costos relativos, LZR, tampoco tendrían raíz unitaria considerando cambios discretos y lo contrario si fueran de nivel. Además, los resultados de las pruebas son relativamente coincidentes con el índice de Quandt en la identificación de los años donde ocurren los cambios estructurales (Tabla 4).

Las cuatro series analizadas presentan cambios estructurales de acuerdo con el estadístico de razón de verosimilitud de Quandt, (Hansen, 2012), el cual se fundamenta en el cálculo anual de la prueba de Chow que verifica la estabilidad de los parámetros, excluyendo el $15 \%$ de los años al comienzo y al final del período, de acuerdo con [10]:

$$
y_{t}=\alpha+\psi D_{t, \tau}+\sum_{i=1}^{p} \theta_{i} D_{t, \tau} y_{t-i}+e_{t}
$$

Donde $\alpha$ será el intercepto; $D_{t, \tau}$ es una variable dicótoma con valores iguales a cero si $t<\tau d$, y uno para el resto; $\psi$ y $\theta$ serán respectivamente los parámetros del cambio discreto y del cambio de nivel de la variable, siendo $\tau$ un parámetro corresponde al año del cambio en términos relativos a la duración del período de análisis $d ; p$ representa el orden de los rezagos de la variable $\gamma$, mientras $e$ serán los errores.

El valor máximo de la prueba $\mathrm{F}$, correspondería al año donde habría quiebre estructural, $\mathrm{QLRT}_{t}^{\star}={ }_{\tau \in \mathrm{T}}^{\max } \mathrm{F}_{t}(\tau)$, calculado con una distribución $\mathrm{F}$ de acuerdo con un $q=5$ restricciones (constante y 4 rezagos) y con valores críticos de 3.7 y 4.5 , para valor probabilísticos menores al $5 \%$ y $1 \%$, respectivamente (Stock; Watson, 2012).

Así para las exportaciones relativas de Colombia respecto a las de Brasil, LXR, (Gráfica 3), se identificaron cambios estructurales en 1909 (3.7^), para los precios relativos, LPR, en $1986\left(13.2^{\star \star}\right)$, para los costos relativos de Colombia con respecto al Brasil, LZR, en 1952 (303.2 $\left.{ }^{\star \star}\right)$ y para la demanda mundial, LY, en $1932\left(4.4^{\star}\right)$. 